
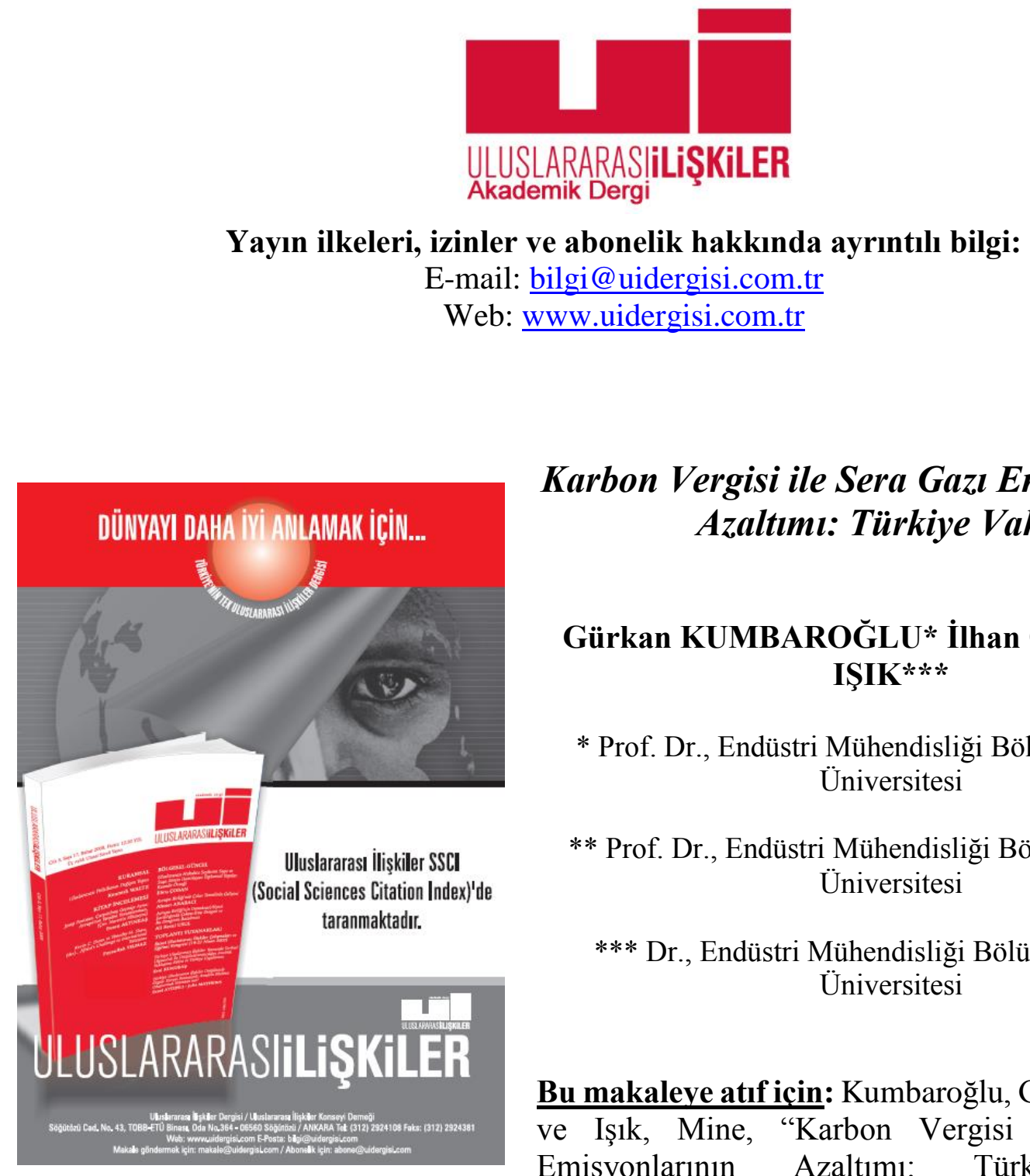

\title{
Karbon Vergisi ile Sera Gazı Emisyonlarının Azaltımı: Türkiye Vakası
}
Gürkan KUMBAROĞLU* İlhan OR** ve Mine IŞIK***

* Prof. Dr., Endüstri Mühendisliği Bölümü, Boğaziçi Üniversitesi

** Prof. Dr., Endüstri Mühendisliği Bölümü, Boğaziçi Üniversitesi

*** Dr., Endüstri Mühendisliği Bölümü, Boğaziçi Üniversitesi

Bu makaleye atıf için: Kumbaroğlu, Gürkan; Or, İlhan ve Işık, Mine, "Karbon Vergisi ile Sera Gazı Emisyonlarının Azaltımı: Türkiye Vakası", Uluslararası İlişkiler, Cilt 14, Sayı 54, 2017, s. 149174.

Bu makalenin tüm hakları Uluslararası İlişkiler Konseyi Derneği'ne aittir. Önceden yazılı izin alınmadan hiç bir iletişim, kopyalama ya da yayın sistemi kullanılarak yeniden yayımlanamaz, çoğaltılamaz, dağıtılamaz, satılamaz veya herhangi bir şekilde kamunun ücretli/ücretsiz kullanımına sunulamaz. Akademik ve haber amaçlı kısa alıntılar bu kuralın dışındadır.

Aksi belirtilmediği sürece Uluslararası Illişkiler'de yayınlanan yazılarda belirtilen fikirler yalnızca yazarına/yazarlarına aittir. UİK Derneğini, editörleri ve diğer yazarları bağlamaz. 


\title{
Karbon Vergisi ile Sera Gazı Emisyonlarının Azaltımı: Türkiye Vakası
}

\author{
Gürkan KUMBAROĞLU \\ Prof.Dr.,Endüstri Mühendisliği Bölümü, Boğaziçi Üniversitesi, İstanbul. E-mail: gurkank@boun.edu.tr \\ Illhan OR \\ Prof. Dr., Endüstri Mühendisliği Bölümü, Boğaziçi Üniversitesi, İstanbul. E-mail: or@boun.edu.tr \\ Mine IŞIK \\ Dr., Endüstri Mühendisliği Bölümü, Boğaziçi Üniversitesi, İstanbul.E-mail: mine.isik@boun.edu.tr
}

\begin{abstract}
ÖZET
Bu çalışmada Türkiye’nin Enerji Sistemi’nin üretim, iletim ve tüketim süreçleri teknolojiler bazında oldukça ayrıntılı olarak modellenmesi gerçekleştirilmiştir. Referans senaryosunun yanı sıra, çeşitli karbon vergisi senaryoları altında kalibre edilen model ile Türkiye'nin hem kısa, hem de uzun vadeli enerji-çevre planlama ve politikalarının oluşumuna destek sağlayabilecek sonuçlar elde edilmiştir. Referans senaryo sonuçlarına göre, Türkiye sera gazı salım değeri baz yılında yaklaşık 400 Mton CO2 iken, bu değerin 2032 yıl itibariyle 955 Mton CO2, 2052 yll itibariyle de 1540 Mton CO2 değerine erişmesi öngörülmektedir. Öte yandan, 10 \$, 20\$ ve 30\$'llk emisyon vergisi ile 2012-2052 periyodu içerisinde toplamda sırası ile, $\% 22.47, \% 24.04$ ve $\% 27.4$ 'lük emisyon azaltımı potansiyeli öngörülmektedir. İlaveten, bu çalışma sektörlerin emisyon vergisi karşısında nasıl davrandıkları detaylı olarak açıklanmaktadır.
\end{abstract}

Anahtar Kelimeler: Enerji modellemesi, sera gazı salım azaltımı, enerji-ekonomi-çevre ilişkileri

\section{Reduction of Greenhouse Gas Emissions with Carbon Tax: The Case of Turkey}

\begin{abstract}
In this study, generation, transmission, and consumption stages are modeled with an in-depth technological detail. In addition to the reference scenario, the model is calibrated under carbon tax scenarios to obtain results that can provide insights for long and short term energy and environment planning and policy generation. According to the reference scenario results, Turkey's greenhouse gas emission values are predicted to reach 1540 Mton CO2 by the year 2052 from its current value of $400 \mathrm{Mton} \mathrm{CO} 2$.

Also, potential emission reductions are projected as $22.47 \%, 24.04 \%$ and $27.4 \%$ under $\$ 10, \$ 20$ and $\$ 30$ emission tax scenarios respectively. Additionally, this study reveals how the sector responds to emission taxes in a comprehensive way.
\end{abstract}

Keywords: Energy modeling, greenhouse gas emission reductions, energy-economy-environment relationship 


\section{Giriş ${ }^{1}$}

Paris İklim Zirvesi’nin de ana gündem maddesi olduğu üzere, küresel ısınma konusunda en önemli vurguyu iklim bilimciler yapmaktadır. Bilimsel analiz sonuçlarına göre, $2^{\circ} C^{\prime}$ lik sıcaklık artışının, iklim sistemindeki olağan koşulların geri döndürülemez şekilde bozulmasına yol açacak eşik değeri olduğu vurgulanmaktadır. ${ }^{2}$ Bu eşiğin aşılmaması için, küresel emisyon hacminin 2050 yılına kadar hiçbir önlem alınmadan gerçekleşmesi öngörülen duruma göre \%50 azaltılmasının gerekli olduğu açıklanmaktadır. ${ }^{3}$

Küresel emisyon hacmi 1990 yılında 20.736 Mton $\mathrm{CO}_{2}$ iken, yaklaşık \%56 artış ile 2013 yılında 32.200 Mton $\mathrm{CO}_{2}$ değerine ulaşmıştır. ${ }^{4}$ Aynı dönemde Türkiye'nin sera gazı salımları ise yılda ortalama \%4 artmış ve toplam sera gazı salımlarının \%86’sı fosil yakıtların kullanımından kaynaklanmıştır. ${ }^{5}$

Sera gazı salım artışının kontrol altına alınması için ulusal ölçekte mümkün olduğunca düşük maliyetli çevre ve enerji politikalarının belirlenmesi gerekmektedir. Karar vericilerin karşılaştıkları en önemli zorluklardan biri öngörülen salım hacmini hedeflenen sınırlar içinde tutmayı sağlayacak en uygun politika araçlarını seçmektir. ${ }^{6}$

Türkiye'nin hızlı salım artışını kontrol altında tutulmasını sağlayacak, etkin ve uygulanabilir politika seçeneklerinin tespiti için gelecek öngörüleri ve stratejileri ile isabetli izdüşümleri verebilecek bilimsel modelleme çalışmalarına ihtiyaç duyulmaktadır. ${ }^{7}$

Bu çalışmada Türkiye'nin ulusal enerji sistemi için yüksek detay seviyesine sahip kuvvetli bir teknolojik veri tabanı içeren bir modelleme çalışması geliştirilmiş, kamuya açık veriler ile kalibre edilerek karbon vergisi senaryoları altında çalıştırılmıştır. Geliştirilen modelleme sistemi vasıtası ile enerji tüketimi ve $\mathrm{CO}_{2}$ salımı arasındaki etkileşim ve bunların sektörel düzeyde maliyetleri ortaya çıkartılmıştır.

Çalışmanın bir sonraki bölümünde, alternatif enerji-ekonomi-çevre modelleri ile ilgili genel kabul gören sınıflandırmalar ve bu sınıflara ait yapısal özellikler literatür taraması kapsamında verilmektedir. 2. bölümde analiz için seçilen modelleme sistemine ait bazı temel formülasyonlar ve genel çalışma mekanizması anlatılmakta, 3. bölümde ise senaryo tanımları ile farklı senaryolar altında elde edilen model sonuçları karşılaştırmalı olarak verilmektedir. Sonuç kısmında ise elde edilen model sonuçlarından ortaya çıkan genel bulgular tartışılmaktadır.

$1 \mathrm{Bu}$ çalışma Boğaziçi Üniversitesi Bilimsel Araştırma Projeleri Koordinatörlüğü tarafından BAP6860 nolu proje kapsamında ve TÜBİTAK tarafından 114M348 nolu proje kapsamında desteklenmiştir.

2 Nygil Goggins, Hybrid Energy-Economy Model For Analysis Of Climate Policy, Yayınlanmamış Yüksek Lisans Tezi, Burnaby, Asia Royal Roads University, 2005, s.1

3 Weaver, Andrew J. et.al., "Long term climate implications of 2050 emission reduction targets", Geophysical Research Letters, Cilt 34, 2007.

4 "Climate Change Indicators in the United States", EPA, 2014, s.1, https://www3.epa.gov/climatechange/science/ indicators/ghg/global-ghg-emissions.html, (Erişim Tarihi 17 Mart 2016).

5 TÜIK, 2013 Greenhouse Gas Emissions Inventory, 2013, s.1, http://www.turkstat.gov.tr/PreHaberBultenleri. do?id=13482, (Erişim Tarihi 20 Kasım 2016).

6 Goggins, Hybrid Energy-Economy Model.

7 Gurkan S. Kumbaroglu, "A model for long-term global air quality and development of efficient control strategies in Turkey”, European Journal of Operations Research, Cilt 102, 1997, s.380- 392. 


\section{Literatür Taraması}

Sera gazı salımları sonucu oluşan iklim değişikliği tehdidi, bu konudaki politikaları destekleyecek analiz modellerine olan ihtiyacı arttırmaktadır. Doğan ihtiyacı karşılamakiçin oluşturulan enerji modellerinin sayısı gün geçtikçe artmaktadır. Bu modeller, hedef gruplarına (politika belirleyiciler, bilimsel ve araştırma toplulukları), kullanım amaçlarına (veri analizi, projeksiyon, simülasyon, optimizasyon, parametrelerin tahmini vs.), bölgesel kapsamlarına (bölgesel, ulusal, küresel), kavramsal çerçevelerine ("tepeden tabana", "temelden yukarı") ve mevcut bilgiye göre değişiklik göstermektedirler. ${ }^{8}$

Model çeşitliliğinin bir sonucu olarak, hangi modelin eldeki özel amaca en uygun olduğuna dair bir soru ortaya çıkmaktadır. Ayrıca, modeller sundukları sonuçların detay düzeylerine ve kapsamlarına göre de farklılık göstermektedirler. Araştırılan soruna en iyi yanıt veren modelin seçimini kolaylaştırmak için, literatürde enerji modelleri arasındaki farklılıkları ve benzerlikleri inceleyerek sınıflama yapan muhtelif çalışmalar vardır. Bu çalışmalardan önemli örnekler aşağıda incelenmektedir.

Literatürde yaygın olarak kabul görmüş iki temel sınıflandırma mevcuttur. Bu sınıflandırmalardan bir tanesi Hourcade et.al. tarafından yapılmış, modellerin amacı, yapısı ve dışsal (ya da girdi) varsayımları olmak üzere, üç önemli faktörü ele alan bir sınıflandırma metodu öne sürmüştür.9 Bir diğer çalışmada Grubb et.al., modellerin yapısal özelliklerini ve çalışma prensiplerini gözeten bir sınıflandırma metodu ortaya koymuştur..$^{10}$ Grubb et.al. enerji modellerini yapısal olarak "tepeden tabana" (top-down) ve "temelden yukarı" (bottom-up) olmak üzere iki sınıfa ayırmıştır. Bu ayrımın yanı sıra, modelin incelediği zaman aralığına göre (kısa vadeli modeller, uzun vadeli modeller), kullandığı metodolojiye göre (optimizasyon vs. simülasyon teknikleri) ve modelin coğrafi kapsamına göre sinıflandırmalar vardır.

“Tepeden tabana” ve "temelden yukarı" yaklaşımlar, enerji sisteminin teknoloji temelli değerlendirmesi ile genel ekonomik sistemin teorik olarak tutarlı tanımına göre birbirlerinden ayrılır.

“Temelden yukarı” grubuna ait olan modeller, içinde ekonominin geri kalan kısmıyla etkileşimlerin hesaba katılmadığı, sadece enerji sektörünün teknolojik girdilerinin detaylı olarak ele alındığı kısmi modelleridir. "Tepeden tabana” modeller ise enerji sistemini oldukça genel bir şekilde, neo-klasik üretim fonksiyonları kullanarak, tanımlar. ${ }^{11}$

Her iki model türünün kuvvetli öğelerini birleştirmek üzere yapılan çalışmalar sonucu, hibrit model olarak isimlendirilen, "temelden yukarı" modellerin teknolojik anlaşlırlığı ve "tepeden tabana" modellerin ekonomik kapsayıcılığını içeren bir model sınıfı ortaya çıkmıştır. ${ }^{12}$

Şekil 1'de görülebileceği gibi, literatürde bu üç popüler başlı̆̆ın altında sınıflandırılabilecek çok sayıda model bulunmaktadır. Buna ilave olarak, her alan yaygın olarak kabul görmüş alt sınıflara bölünmüştür. Bir sonraki bölümde, modelleme yaklaşımı türüne göre üç ana sınıf olan, "tepeden tabana”, “temelden yukarı” ve hibrit modeller kısaca açıklanacak ve alt kırılımlara ait bilgiler verilecektir.

8 Andrea Herbst et.al. "Introduction to Energy Systems Modelling”, Swiss Society of Economics and Statistics, Cilt 148, No.2, 2012, s.111-135.

9 Jean C. Hourcade et.al., "Estimating The Costs Of Mitigating Greenhouse Gases" Economic and Social dimensions of climate change, 1996, s.263-296.

10 Michael Grubb et.al., “The Cost Of Limiting Fossil-Fuel CO2 Emissions: A Survey And Analysis”, Annual Review of Energy and the Environment, Cilt 18, 1993, s.397-478.

11 Löschel, Andreas, “Technological Change In Economic Models of Environmental Policy: A Survey”, Ecological Economics, Cilt 43, 2002, s.105-126.

12 Proenca, Sara A. ve Miguel St. Aubyn, "Hybrid Top-Down/Bottom-Up Model For Energy Policy Analysis in a Small Open Economy-The Portuguese Case”, 2009, s.1, http://ideas.repec.org/a/eee/eneeco/v38y2013icp176-185.html, (Erişim Tarihi 20 Kasım 2016). 
Şekil 1 Modelleme Yaklaşımına Göre Enerji Model Sınıflandırması

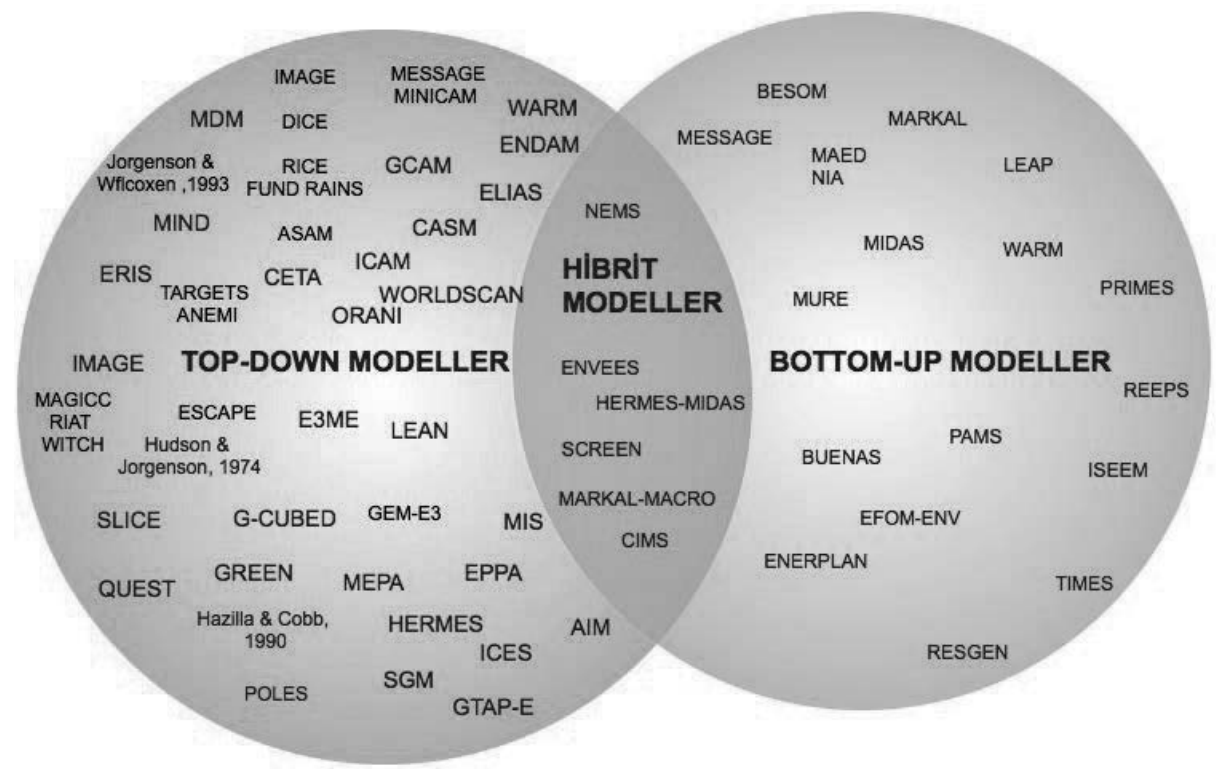

\section{Tepeden Tabana (Top-Down) Modeller}

Bu modellerde sistemi değerlendirmek için bazı temel ekonomik değişkenler kullanılmıştır. Tepeden tabana modeller; bir denge çerçevesinde, ekonominin girdileri ve çıktıları arasındaki toplam ilişkiyi tahmin etmek için, parametreler kullanan bir mekanizmaya dayanan ekonomik modeller olarak düşünülebilir. ${ }^{13} \mathrm{Bu}$ modeller, sistemin ekonomik girdileri ve mekanizmasını dikkate alsalar da, teknolojileri detaylı olarak irdelemedikleri için, teknolojik gelişmeleri, değişimleri ve inovasyonları temsil etme yeteneğine sahip değildirler. Bunun sonucunda tepeden tabana modeller enerji sistemini mevcut yapıdan farklılaştırma çabalarını değerlendirmekte yetersiz kalmaktadırlar. ${ }^{14}$

“Tepeden tabana” yaklaşımı altında sınıflandırılan modelleme metodolojileri şu şekilde sıralanabilir: Girdi-Çıktı Modelleri, Entegre Edilmiş Değerlendirme Modelleri, Hesaplanabilir/ Uygulamalı Genel Denge Türü Modeller ve Ekonometrik Modeller.

Girdi-Çıktı (IO) modeli Wassily Leontief tarafından geliştirilmiştir. Bu modelde sektör bazında tanımlanan ekonomik yapı doğrusal bir denklem olarak sunulmuştur. Bu tür bir modelde ekonomik yapının ayrıntılı bir tanımı, sektör bazında ara talep, nihai talep ve birincil girdi gereksinimleri şeklinde elde edilmektedir. Ayrıca model, ekonomik faaliyet seviyesi ve bu seviyeye karşılık gelen çevre üzerine etki arasındaki ilişkiye dair bilgi verebilmektedir. ${ }^{15}$

IO modelleri sadece talep odaklı politikaların doğrudan ekonomik ve sektörel etkilerini araştırmak için değil, aynı zamanda ekonomi üzerinde dolaylı etkilerini araştırmada ve belirli bir değişimin etkisini incelemek için durumsal tahminler yapmada da en yaygın biçimde faydalanılan

13 Mark Jaccard ve Nic Rivers, “Useful Models For Simulating Policies To İnducetechnological Change”, Energy Policy, Cilt 34, No.15, 2005, s.2028-2047.

14 Hourcade et.al., "Estimating The Costs of Mitigating Greenhouse Gases".

15 Luis M.G. Cruz, "Energy-Environment-Economy Interactions: An Input-Output Approach Applied to the Portuguese Case", Environment and Development: Globalisation \& the Challenges for Local \& International Governance, Sousse, Tunisia, 2002. 
modellerdir. ${ }^{16}$ Faydalarının yanında, ilkel IO modelleri uygulama alanlarının ulusal ölçekle sınırlı olmasından dolayı eleştirilmektedir. Buna ilave olarak, enerji talebi ve arzı arasındaki ikame ve geri bildirim mekanizmasını da kapsamamaktadırlar. ${ }^{17}$

Bazı çalışmalarda ise diğer bir yaklaşım olan entegre değerlendirme modellerinin; bilginin yapılandırılması, belirsizliklerin nitelendirilmesi ve büyük bir sistemin parçaları arasındaki geri bildirimlerin enerji ve çevre politikası ilişkisinde olduğu gibi gözlemlenmesi için kullanışlı bir araç olduğundan bahsedilmektedir. ${ }^{18}$

Ekonometrik modeller ise, denge varsayımlarını göz önüne bulundurmayan zaman serisi analizi, yatay kesit analizi gibi ekonometrik çözümlemeler kullanan denklemlerden oluşur. Bu tür modeller ekonomik yapıyı ayrıntılı şekilde içerir. ${ }^{19}$ Ekonometrik modeller kısa vadeli analizler için "tepeden tabana" modellerden daha isabetli projeksiyonlar üretebilir; ancak, uzun vadeli incelemelerde güvenilir sonuçlar verememektedirler. ${ }^{20}$ Eleştirildikleri bir diğer nokta ise, bu modellerin hızlı gelişen fiyat dalgalanmaları ile başa çıkamamalarıdır. ${ }^{21}$

\section{Temelden Yukarı (Bottom-Up) Modeller}

“Temelden yukarı" modeller enerji sistemini teknolojik ayrıntılarıyla tanımlamaktadırlar. Gelecek teknolojilerin temel maliyet ve performans özelliklerini de gerektiren yüksek teknolojik ayrıntı ile üretilmişlerdir. ${ }^{22}$ "Temelden yukarı" modeller; teknoloji uygunluğu, enerji kaynaklarının potansiyeli, salımlar vs. ile kısıtlanan enerji talebini karşılamaya yönelir olarak en düşük maliyetli enerji teknolojileri kombinasyonunu bulmaya çalışır. Bu modeller enerji sektörünün, ekonominin geri kalan kısmıyla etkileşimlerini gözlemleme yeteneğine sahip değildir. Ayrıca, bu tür modellerde ekonomik ajanların sadece dişsal maliyet kalemleri temsil edilmektedir.

Temelden yukarı enerji-ekonomi modellerinde farklı metodolojik yaklaşımlar kullanılmaktadır. Literatürde, simülasyon, optimizasyon ve muhasebe modelleri olmak üzere, genel kabul gören üç metodolojik kategori bulunmaktadır.

Simülasyon modelleri, optimal veya rasyonel örgü ile ilişkili olmayan, gözlemlenen ve beklenen mikro-ekonomik davranışı temsil etmek için kullanılır. Tüketicilerin ve üreticilerin çeşitli durumlardaki davranışlarını taklit ederler. Bu tür modeller son kullanıcının çeşitli faktörleri (enerji güvenliği vb.) göz önünde bulundururken teknoloji seçimi davranışını açığa çıkarmaya çalışırlar. ${ }^{23}$

16 Robert Pollin et.al., The Economic Benefits of Investing in Clean Energy: How the Economic Stimulus Program and New Legislation can Boost US Economic Growth and Employment, Published Studies, 2009.

17 Claudia Kemfert, "Climate Coalitions and International Trade: Assessment of Cooperation Incentives by Issue Linkage", Energy Policy, Cilt 32, 2004, s.455-465.

18 Evan G.R. Davies ve Slobodan P. Simonovic, "Global Water Resources Modeling With an Integrated Model of The Social-Economic-Environmental System”, Advances in Water Resources, Cilt 34, No,6, 2011, s.684-700.

19 Löschel, "Technological Change”.

20 Richard Loulou et.al. "Documentation for the TIMES Model, Part II. Energy Technology Systems Analysis Programme” (ETSAP), 2005, s.1, http://www.iea-etsap.org/web/docs/timesdoc-intro.pdf (Erişim Tarihi 20 Haziran 2016).

21 Gurkan S. Kumbaroglu, "Environmental Taxation within a Bottom-Up framework of Energy-Economy Interactions: The Model ENVEES, Proceedings of the Methodical Workshop on Approaches in the Integration of Energy and Economy Models for the Evaluation of Future Strategies", University of Stuttgart Institute of Energy Economics and the Rational Use of Energy, 2002, s.93-103.

22 Christoph Böhringer ve Thomas F. Rutherford, “Combining Bottom-Up and Top-Down”, Energy Economics Cilt 30, No.2, 2008, s.574-596.

23 Luis Mundaca et.al., "Evaluating Energy Efficiency Policies with Energy-Economy Models", Annual Review of Environment and Resources, Cilt 35, No.1, 2010, s.305-344. 
Optimizasyon modelleri enerji sistemlerinin çeşitli kısıtlamalara $\left(\mathrm{CO}_{2}\right.$ salım hedefi, belirlenmiş bir kaynak için en yüksek kullanılabilirlik hedefi vb.) dayanan teknoloji yapılandırmalarını dikkate alırken en düşük maliyetli çözümleri bulmayı amaçlar. MARKAL, TIMES, EFOM-ENV ve MIDAS bu sınıfa ait olan en popüler enerji-çevre modellemelerinden bazılarıdır. ${ }^{24}$

Diğer bir grup olan muhasebe modelleri ise varsayımlara (sosyal, ekonomik, teknolojik) dayanan bir yapıya sahiptir. Modeli kuran kişi, her faktör için gelecekte beklenen neticeleri model içerisinde tanımlamak zorundadır, yani tutarlılık performansı modelcinin başarısına aittir. Bu sınıf içinde Ulusal Etki Analizi (NIA) gibi sadece muhasebe çerçevesine sahip olan modeller olmasına rağmen ${ }^{25}$, diğer bazı modeller muhasebeyi benzetim gibi diğer sınıflarla birleştirmeyi tercih etmektedir. Örnek olarak LEAP, BUENAS, ve PAMS modelleri, enerji-ekonomi-çevre modellemesinin muhasebe ve benzetim türüne ait modellerdir.

\section{Hibrit Modeller}

Önceden bahsedildiği gibi, "temelden yukarı" modeller, oldukça ayrıntılı teknoloji bilgisi içeren kısmi denge gösterimi kullanırlarken; “tepeden tabana” modeller tüm ekonomiyi kapsayan bir perspektif içerirler. Geleneksel tepeden tabana modeller enerji-ekonomi etkileşimlerini incelerken enerji sisteminin sınırlı temsili sebebiyle eleştirilmektedir. Doğası gereği, tepeden tabana modeller enerji politika seçeneklerinin isabetli değerlendirilmesi için gerekli teknolojik altyapıya sahip değildir. Temelden yukarı modeller ise, farklı enerji-iklim politik enstrümanlarının sonucunda ortaya çıkan makroekonomik geri bildirimleri yakalayamamaktadır. Her model türünün sahip olduğu eksiklikler nedeniyle, yakın zamanda yapılan çalışmalar iki modelleme yaklaşımının birleştirilmesi gerekliliğini ortaya koymuştur. Bu ihtiyacı gidermek için, "temelden yukarı" modellerin teknolojik anlaşılırlığı ile "tepeden tabana” modellerin ekonomik kapsamlılı̆̆ını birleştiren hibrit modeller geliştirilmiştir. ${ }^{26}$ NEMS $^{27}$, MARKAL-Macro ${ }^{28}$ ve MESSAGE-Macro ${ }^{29}$, ENPEP $^{30}$, ENVEES $^{31}$, ETA MACRO ${ }^{32}$, HERMES-MIDAS ${ }^{33}$, SCREEN ${ }^{34}$, CIMS ${ }^{35}$ hibrit modellemeye örnek olarak verilebilir.

24 Gurkan S. Kumbaroglu ve Reinhard Madlener, "Energy and Climate Policy Analysis with the Hybrid Computable General Equilibrium Model SCREEN: The Case of the Swiss CO2 Act” Annals of Operations Research, Cilt 121, No.1, 2003, s.181-203.

25 Ali Hainoun et.al., "Analysis of The Syrian Long-Term Energy and Electricity Demand Projection Using The End-Use Methodology”, Energy Policy, Cilt 34, No.14, 2006, s.1958-1970.

26 Proenca ve Aubyn, "Hybrid Top-Down/Bottom-Up Model”.

27 Cooper Richey, “Methodology For Tax Rebate Analysis”, 1998, s.1, http://enduse.lbl.gov/SharedData/taxmethod.rtf, (Erişim Tarihi 15 Kasım 2016).

28 Subhes C. Bhattacharyya ve Govinda R. Timilsina, “A Review of Energy System Models”, International Journal of Energy Sector Management, Cilt 4, No.4, 2010, s.494-518.

29 Sabine Messner ve Leo Schrattenholzer, "MESSAGE-MACRO: Linking An Energy Supply Model with a Macroeconomic Module and Solving it İieratively”, Energy, Cilt 25, No.3, 2000, s.267-282.

30 William A. Buehring et.al., ENPEP: An Integrated Approach for Modelling National Energy Systems, Argonne National Laboratory, Lemont, 1991.

31 William D. Nordhaus ve Zili Yang, "A Regional Dynamic General-Equilibrium Model of Alternative Climate Change Strategies”, American Economic Review, Cilt 886, 1996, s.741-765.

32 Richard S. J. Tol, "On the Optima Control of Carbon Dioxide Emissions: An Application of Fund", Environmental Modelling and Assessment, Cilt 2, 1997, s.151-163.

33 Hadi Dowlatabadi, "Sensitivity of Climate Change Mitigation Estimates to Assumptions About Technical Change", Energy Economics, Cilt 20, No.5, 1998, s.473-493.

34 Karen Fisher-Vanden et.al., The Second Generation Model Of Energy Use, The Economy, and Greenhouse Gas Emissions, Pacific Northwest National Laboratory, 1993.

35 Nordhaus ve Yang, "A Regional Dynamic General-Equilibrium Model”. 


\section{Metodoloji}

$\mathrm{Bu}$ çalışma kapsamında, Türkiye enerji sektörünü, enerji kaynakları temini, üretimi, iletimi, dağıtımı, tüketimi, talep kalemleri, ilgili yatırım faaliyetleri, harcamaları, çevreye ve ekonomiye etkileri ile birlikte, orta ve uzun vadede yansitırken, enerji arzı ile talebini, gene orta ve uzun vadede dengeleyen, TIMES modelleme sistemi kullanılmıştır. TIMES modelleme sisteminin temellerini MARKAL oluşturmaktadır. MARKAL yaygın kullanılan bir doğrusal programlama modelidir. ${ }^{36}$ İçsel teknolojik öğrenmeye dayanan enerji sistemini de hesaba katan kısmi denge metodolojisi altında çalışan "Temelden yukarı" sınıfına dâhil modelleme yaklaşımını esas almaktadır. Standart MARKAL Uluslararası Enerji Ajansı ve Enerji Teknoloji Sistemleri Analiz Programı Üyeleri tarafından 1980’lerde enerji sistemlerinin uzun dönem analizi için geniş ölçekli ve talep odaklı bir model olarak ortaya çıkmıştır. MARKAL, Brookhaven Enerji Sistemi Optimizasyon Modelinin (BESOM) geliştirilmiş versiyonu olarak bilinir (BESOM sadece ulusal seviyede en verimli kaynak dağılımını açığa çıkarmayı hedeflemektedir). ${ }^{37}$

Güvenilir sonuç vermeleri ve modellenen yapıyı detaylı olarak temsil edebilme güçlerinin sonucu olarak, MARKAL ve TIMES, 50 ülkedeki 80 enerji araştırma kurumu tarafından farklı alanlarda yapılan çalışmalarda tercih edilen en popüler iki "temelden yukarı" enerji modeldir. ${ }^{38}$

TIMES bir kısmi denge modelidir. Önceden belirlenmiş zaman aralığında, toplam enerji talebini karşılamak için en uygun teknoloji setini ortaya çıkarmayı hedefler. Model söz konusu piyasada mükemmel rekabetin var olduğu kabulü ile çalışır. TIMES modeli, bir dizi denklem ve eşitsizlikten oluşmaktadır. Bunlar topluca kısıtlamalar ve objektif fonksiyonlar olarak ifade edilir. Genellikle enerji sisteminin toplam indirilmiş maliyetleri olarak alınır. TIMES, MARKAL'daki temel modelleme paradigmasını içerir ve MARKAL'da olduğu gibi model içerisinde farklı politika ve senaryoları analiz etmek mümkündür. Dahası, TIMES’’n işlevselliği enerji sistemlerinin yapısal özelliklerinin model içerisindeki tanımlarına yeni özellikler katılmasıyla genişletilmiştir. TIMES modeli içinde kullanıcı tarafından nihai kullanım enerji taleplerinin tanımlanması gerekmektedir. Bununla birlikte, kullanıcı var olan enerji stoklarını ve teknolojilerini her sektör için tanımlamak zorundadır. Model, analiz periyodu içerisinde kullanıma girmesi planlanan tüm ileri teknolojileri de kapsar. TIMES modeli, enerji hizmetlerini minimum maliyette sağlayarak toplam talebi karşılamak için; enerji ticareti, hangi enerji ekipmanına yatırım yapılması gerekliliğini, ana enerji kaynaklarına ait arza her bölge için karar verir. ${ }^{39}$

Literatürdeki çalışmalar incelendiğinde TIMES modeli ile gerçekleştirilmiş ve kapsamlı sonuçlar elde edilmiş örneklere rastlanmaktadır. Bunlara örnek olarak, Liu et.al. tarafından Çin Halk Cumhuriyeti için oluşturulan TIMES modeli verilebilir ${ }^{40}$. Liu et.al. bu çalışmada sürdürülebilir enerji, çevresel gelişme stratejisi gibi Çin'in enerji politikasına yönelik 2050 yılına kadarki projeksiyonu elde etmeyi ve senaryo analizleri yapmayı amaçlamışlardır.

\footnotetext{
36 Richard Loulou et.al., "Documentation for the MARKAL Family of Models”, 2004, s.1, http://www.iea-etsap.org/web/ mrkldoc-i_stdmarkal.pdf, (Erişim Tarihi 20 Haziran 2016).

37 Bhattacharyya ve Timilsina, "A Review of Energy System Models".

38 Loulou et.al., "Documentation for the TIMES model".

39 Ibid.

40 Liu Jia et.al., "Scenario Analysis of China’s Future Energy Demand Based on TIMES Model System”, Energy Procedia, Cilt 5, 2011, s.1803-1808.
} 
Bir diğer çalışma ise Vaillancourt et.al. tarafından gerçekleştirilmiş, nükleer enerji kullanımın, dünya genelindeki sera gazı salım değerindeki azalmaya olan katkısını dünya üzerindeki tüm bölgeleri içerecek şekilde, 2000-2100 yılları arasındaki 100 yıllık zaman dilimi için incelemişlerdir. ${ }^{41}$

TIMES modeli toplam enerji sistemi harcamalarını enküçüklemeyi amaçlar bunu yaparken doğrusal programlama yaklaşımını kullandığı için bu amaca ulaşırken; arz-talep dengesi, kapasite, girdi çıktı ilişkilerini içeren kısıtları göz önünde bulundurur. TIMES modeli içerisinde bulunan kısıt yapıları haricinde, kullanıcı tarafından özel kısıtların model içerisinde oluşturulmasına da olanak tanır.

TIMES modeli enerji alanında oluşturulacak her türlü plan, politika ve strateji için, enerji üretim ve tüketim teknolojileri üzerine oldukça kapsamlı sonuçlar sağlamaktadır. ${ }^{42}$

Bu modelleme sistemi, çeşitli yatırım, teknolojik gelişim, kaynak temin, çevrim, tüketim, talep, fiyat farklılaşması ve sera gazı salımlarının kısıtlanması gibi, karar politikalarının ve parametrelerin, Ulusal enerji sektörü, ekonomi ve çevre üzerine etkilerinin incelenmesine ve gözlenmesine olanak sağlayacak bir yapı oluşturmaktadır. Yukarıda belirtilen gerekçelerden ötürü bu çalışmada TIMES modelleme sisteminden yararlanılmaktadır.

Sistem amaç fonksiyonu ve olurlu bölgeyi oluşturan kısıtlar üzerinden en iyiye gitmeyi amaçlar. TIMES belirli bir zaman aralığına ait toplam net maliyeti minimize (veya eşdeğer net toplam faydayı maksimize) ederken, bir dizi kısıtlamaları da tatmin ederek, belirli bir zaman ufkunda sistemi yapılandırır. TIMES tüm yatırım kararlarını gelecekteki olaylar hakkında tam bilgiye sahip olunduğu kabulü altında, dinamik bir şekilde yapar.

$$
\begin{aligned}
\operatorname{reg\_ obj}(z)= & \sum_{y \in(-\infty,+\infty)} \operatorname{disc}(y, z) \\
& \times\{\operatorname{invcost}(y)+\operatorname{invtaxsub}(y)+f i x c o s t(y)+\operatorname{fixtaxsub}(y) \\
& +\operatorname{varcost}(y)-\operatorname{salvage}(y)\}
\end{aligned}
$$

- reg_obj(z): indirgenmiş amaç fonksiyonu

- $\operatorname{disc}(\mathbf{y}, \mathbf{z}):$ y yılının başında yapılmış olan 1 ödemeyi z yılının başına indirgeme katsayısı.

- invcost $(y):$ y yılında yapılan toplam yatırım maliyeti

- invtaxsub(y): y yılında yapılan yatırımlara ait toplam vergi tutarı

- $\operatorname{fixcost}(\mathbf{y})$ : y yılında oluşan sabit yıllık maliyet

- fixtaxsub(y): sabit yıllık maliyeti için gerçekleşen vergi veya devlet teşviki tutarı.

- $\operatorname{varcost}(\mathbf{y}):$ y yılında oluşan değişken maliyet

- salvage(y): y yılına indirgenecek olan, yatırımlara ait toplam hurda değeri

41 Kathleen Vaillancourt et.al., "The Role of Nuclear Energy in Long-Term Climate Scenarios: An Analysis with the WorldTIMES Model”, Energy Policy, 2008, s.2296-2307.

42 Ad J. Seebregts et.al., "Energy/Environmental Modeling with the MARKAL Family of Models", Energy and Environment, 2001, s.3-5. 
Şekil 2 Modeli Çalışma Mekanizması

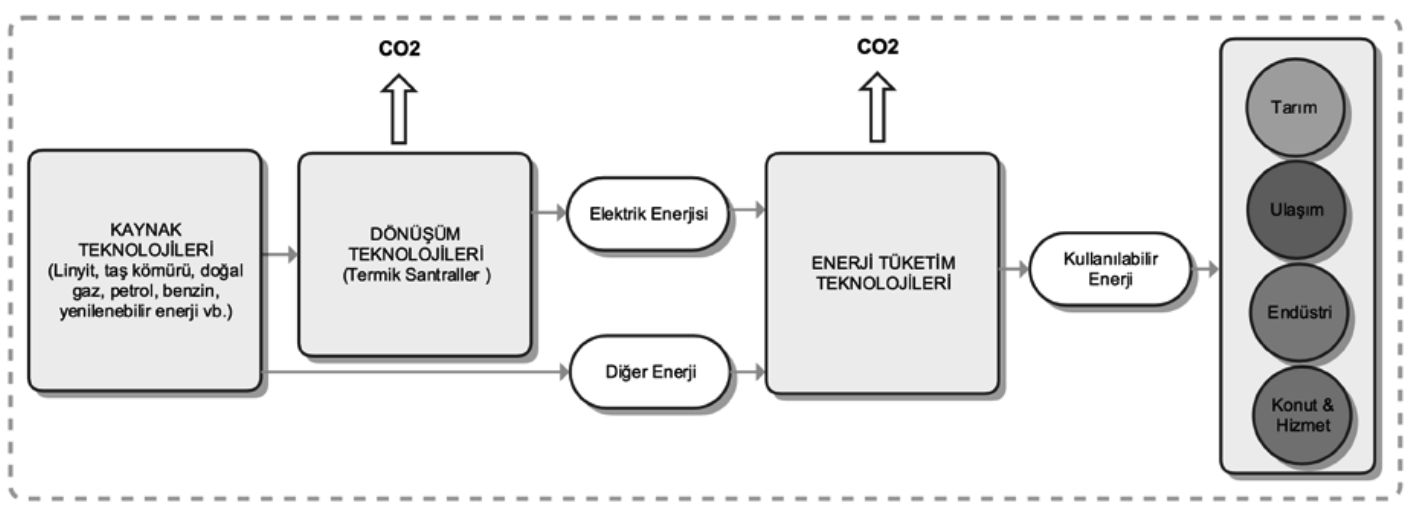

Şekil 2'de görüldüğü gibi, nihai enerji talepleri her bir sektör için tanımlanmış olan talep teknolojileri tarafından kaynak yakıtların tüketilmesi ile karşılanır. Model içerisinde Türkiye'yi temsilen dört farklı sektör tanımlanmışır. Bunlar sırasıyla; ulaştırma, konut ve hizmet, endüstri ve tarım sektörleridir. Model amaç fonksiyonunu eniyilemeye çalışırken bazı kısıtları gözetmek zorundadır. Bu kısıtlar aşağıdaki ana gruplara ayrılmaktadırlar;

\section{Kapasite Transfer Denklemleri}

Modelde herhangi bir teknolojiye yapılan yatırım, teknolojinin ekonomik ömrüne bağlı olarak, toplam kapasiteyi artırıcı etki yaratır. Bu ömrün sonunda ise, adı geçen teknoloji hurdaya çıkartıldığından, modeldeki toplam kapasite aynı miktarda azalacaktır. Bu nedenle herhangi bir dönemde mevcut toplam kapasiteyi hesaplamak için model o zamana kadar o teknolojiye yapılan tüm yatırımları ve onların ömürlerini dikkate alır. "Kapasite Transfer Denklemleri" mevcut teknolojilerin eskime ve hurdaya çıkmaları ve aynı amaca hizmet eden yeni teknolojilerin devreye girmeleri ile dönemsel olarak sağlanan, ayrıca dönemler arasındaki kapasite aktarımını yansıtan denklem setidir. Örneklemek gerekir ise;

$$
\operatorname{capt}(r, t, p)=\sum_{t^{\prime<l i f e}(r, t, p)} n \operatorname{cap}\left(r, t^{\prime}, p\right)+\operatorname{resid}\left(r, t^{\prime}, p\right)
$$

- $\operatorname{capt}(\mathbf{r}, \mathbf{t}, \mathbf{p}): \mathrm{t}$ dönemi içerisinde $\mathrm{r}$ bölgesindeki $\mathrm{p}$ teknolojisine ait toplam kapasite

- life(r,t,p): $t$ dönemi içerisinde $r$ bölgesindeki $p$ teknolojisine ait toplam teknik ömür

- ncap $(\mathbf{r}, \mathbf{t}, \mathbf{p})$ : $\mathrm{t}$ dönemi içerisinde $\mathrm{r}$ bölgesindeki $\mathrm{p}$ teknolojisine ait toplam yeni kapasite yatırımı

- $\operatorname{resid}(\mathbf{r}, \mathbf{t}, \mathbf{p}): \mathrm{t}$ dönemi içerisinde $\mathrm{r}$ bölgesindeki $\mathrm{p}$ teknolojisine ait toplam rezidüel kapasite

\section{Kapasite Kullanım Denklemleri}

Modelde her teknoloji için dönemlik kullanılabilirlik faktörleri girilebilir. Model bazı dönemlerde kullanılabilir kapasitenin sadece bir kısmını kullanmayı seçebilir. Modelde bir veya birkaç teknolojinin belli dönemlerde tüm kapasitesini kullanması için şart da yaratılabilir. 'Kapasite Kullanım Denklemleri' 
teknolojilerin kapasite seviyeleri üzerindeki kullanılabilirlik ve şartları tanımlayan denklem setidir. Her teknoloji $\mathrm{k}$, periyod $\mathrm{t}$, bölge $\mathrm{r}$ ve zaman dilimi s, için teknolojinin kapasite kullanımı kullanıcı tanımlı emre amadelik faktörünün toplam kapasite ile çarpımını geçemez.

$$
\operatorname{act}(r, t, p, s)=\sum_{c \in p c g} \frac{\operatorname{flow}(r, t, p, c, s)}{\operatorname{actflo}(r, t, p, c)}
$$

- $\operatorname{act}(\mathbf{r}, \mathbf{t}, \mathbf{p}, \mathbf{s}): \mathrm{t}$ dönemi içerisinde $\mathrm{s}$ zaman dilimine ait $\mathrm{r}$ bölgesindeki $\mathrm{p}$ teknolojisine ait aktivite seviyesi

- $\operatorname{flow}(\mathbf{r}, \mathbf{t}, \mathbf{p}, \mathbf{c}, \mathbf{s}))$ : $\mathrm{t}$ dönemi içerisinde $\mathrm{s}$ zaman dilimine ait $\mathrm{r}$ bölgesindeki $\mathrm{p}$ teknolojisine giren c enerji taşıyıcısı akışı

- $\operatorname{actflo}(\mathbf{r}, \mathbf{t}, \mathbf{p}, \mathbf{s}): \mathrm{t}$ dönemi içerisinde $\mathrm{s}$ zaman dilimine ait $\mathrm{r}$ bölgesindeki $\mathrm{p}$ teknolojisine ait aktivite çevrim faktörü

\section{Denge Denklemleri}

Modelde her dönemde ve her bir enerji taşıyıcısı için ithalat artı üretim toplamı, tüketim artı ihracat toplamından büyük veya eşit olmalıdır. 'Denge Denklemleri' arz ve talep arasındaki bu dengeyi sağlayan denklem setidir.

$$
\begin{gathered}
{\left[\sum_{p \in \operatorname{top}_{(r, p, r o u t)}} \operatorname{flow}(r, t, p, c, s)+\operatorname{sout}(r, t, p, c, s) \times \operatorname{stg}_{\text {eff }(r, p)}\right.} \\
+\sum_{p, c \in \operatorname{prc} \text { ire }(r, p, c, i m p)} \operatorname{trade}(r, t, p, c, s, i m p) \\
\left.+\sum_{p} \operatorname{release}(r, t, p, c) * \operatorname{ncap}(r, t, p, c)\right]
\end{gathered}
$$

$\left[\sum_{p \in \operatorname{top}_{\left(r, p, r^{\prime \prime} i n^{\prime \prime}\right)}} f l o w(r, t, p, c, s)+\sin (r, t, p, c, s)+\right.$

$\sum_{p, c \in p r c_{-} i r e\left(r, p, c, " \exp ^{\prime}\right)} \operatorname{trade}\left(r, t, p, c, s, " \exp ^{\prime}\right)+\sum_{p} \operatorname{sink}(r, t, p, c) * n c a p(r, t, p, c)+$ $f r(c, s) * d m(c, t)]$

- top(r,p,c,"in/out"): r bölgesindeki p teknolojisi için gerçekleşen c enerji taşıyıcısına ait toplam yakıt girişi/çıkışı.

- rpc_ire(r,p,c,"imp/exp”): r bölgesine p teknolojisi aracılığıyla yapılan c enerji taşıyıcısına ait toplam ithalat/ihracat değeri.

- stg_eff(r,p): $r$ bölgesindeki $p$ teknolojisine ait depolama verimi 
- com_ie(r,t,c): t dönemi içerisinde r bölgesindeki c enerji taşıyıcısına ait yapısal verim değeri

- $\operatorname{release}(\mathbf{r}, \mathbf{t}, \mathbf{p}, \mathbf{c})$ : $\mathrm{t}$ döneminde sökülecek olan $\mathrm{r}$ bölgesindeki p teknolojisinden kalan c enerji taşıyıcı miktarı

- $\operatorname{sink}(\mathbf{r}, \mathbf{t}, \mathbf{p}, \mathbf{c}): \mathrm{t}$ dönemi içerisinde $\mathrm{r}$ bölgesindeki $\mathrm{p}$ teknolojisine ait bir birimlik kapasite artışı için gereken c tipi enerji taşıyıcı miktarı.

- $\mathbf{f r}(\mathbf{s})$ : s zaman diminin yıla oranı

\section{Üst Seviye Elektrik Rezervi}

Elektrik "stoklanamayan" bir enerji türü olduğu için, her dönemde ve bu dönemin her mevsimi ve günün her saatinde, üretilen elektrik artı ithalat en az tüketim artı ihracat ve iletim kayıplarını karşılayacak kadar olmalıdır.

$$
\begin{aligned}
\sum_{c=\text { cmg yi üreten p }} & \operatorname{capunit}(r, p) \times \operatorname{peak}(r, p, c, s) \times f r(s) \times \operatorname{cap}(r, v, t, p) \\
& \times \operatorname{actflo}(r, v, p, c) \\
& +\sum_{c=p c g y i \text { üreten } p \text { teknolojileri }} \operatorname{peak}(r, p, c, s) \times \operatorname{flow}(r, t, p, c, s) \\
& +\operatorname{trade}(r, t, p, c, s, i) \\
\geq & {[1+\operatorname{reserve}(r, t, c, s)] } \\
& \times\left[\sum_{c \text { yi tüketen } p \text { teknolojileri }} \operatorname{flow}(r, t, p, c, s)+\operatorname{trade}(r, t, p, c, s, e)\right]
\end{aligned}
$$

- peak(r,p,c,s): s zaman dilimi içerisinde r bölgesindeki p teknolojisine ait c enerji taşıyıcısına olan en yüksek talep.

Yukarıdaki denklem setleri üzerine kurulacak ve kalibrasyonu yapılacak modelin çözümünde (ve politika önerilerinin belirlenmesinde), planlama ufku içindeki her beş yıllık dönemde, kaynak, çevrim, iletim ve tüketim teknolojileri ile kapasite kullanımlarının seçimine yönelik bir "kısıtlı eniyileme” yaklaşımı yol gösterici olmaktadır. Bu çerçevede, verimlilik ve işletim/yatırım maliyetleri ile ekonomik ömürler öncelikle göz önüne alınmakta, ancak (varsa) o kaynak/teknoloji için belirlenen en az / en çok kapasite kullanım kısıtları ile genel ve sektörel emisyon kısıtları titizlikle uygulanır.

$\mathrm{Bu}$ yaklaşımın bir sonucu olarak, modele dişsal olarak girilen sektörel ve alt kırılımlarına ait dönemsel enerji taleplerinin karşılanmasında, hangi teknolojilerin ve enerji kaynaklarının ne ölçüde kullanılacağını, ilgili teknoloji ve kaynakların maliyet, verimlilik, ekonomik ömür ve sera gazı salım özelliklerini dikkate alarak, model içsel olarak model tarafından belirlenir.

Bu çalışma kapsamında Türkiye’nin mevcut enerji altyapısı ile talep sektörleri modellenmiş ilaveten 2052 yılına kadar belirtilen koşullar altında sistemin nasıl şekilleneceğini açıklamak adına senaryo çalışmaları yapılmıştır. Temel varsayımların bulunduğu "Referans Senaryo" ile karbon fiyatlandırmasının enerji sektöründeki etkisini gözlemleyebilmek adına 3 farklı fiyat seçeneği için 
emisyon senaryoları oluşturulmuştur. Bunlar sırası ile "CO2-10, CO2-20, CO2-30" olmak üzere emisyon maliyetinin ton başına $10 \$, 20 \$$ ve 30 \$ oluğu kabulü ile çalışmaktadır. Senaryoların hepsinde Tablo 1'de belirtilen kabuller geçerli tutulmuştur.

Tablo 1 Referans Senaryo Kapsamında Yapılan Kabuller

\begin{tabular}{|c|c|c|}
\hline Sektör & Varsayımlar & \\
\hline \multirow{7}{*}{$\begin{array}{l}\text { Elektrik } \\
\text { Üretim } \\
\text { Sektörï* }\end{array}$} & Kömür & Elektrik enerjisi üretimi amaçlı kömür kullanımı model seçimine bırakılmıştır. \\
\hline & Doğalgaz & $\begin{array}{l}\text { Elektrik enerjisi üretimi amaçlı doğalgaz kullanımı arz kaynaklarına ilişkin belli } \\
\text { kapasite ve fiyat kısıtları altında model seçimine bırakılmıştır. }\end{array}$ \\
\hline & Nükleer & Nükleer teknolojinin yatırım seçenekleri arasında olmadığı varsayılmıştır. \\
\hline & Hidrolik & $\begin{array}{l}\text { Hidrolik enerji bazlı elektrik üretiminde ekonomik erişilebilir kapasitenin } \\
\text { Türkiye yenilenebilir enerji strateji belgesi ile uyumlu olacağı varsayılmıştır. }\end{array}$ \\
\hline & $\begin{array}{l}\text { Rüzgâr }+ \\
\text { Güneş }\end{array}$ & $\begin{array}{l}\text { Rüzgâr ve Güneş enerjisi bazlı elektrik üretiminde ekonomik erişilebilir } \\
\text { kapasitenin Türkiye yenilenebilir enerji strateji belgesi ile uyumlu olacağı } \\
\text { varsayılmıştır. }\end{array}$ \\
\hline & Jeotermal & $\begin{array}{l}\text { Jeotermal enerji bazlı elektrik üretiminde ekonomik erişilebilir kapasitenin } \\
\text { Türkiye yenilenebilir enerji strateji belgesi ile uyumlu olacağı varsayılmıştır. }\end{array}$ \\
\hline & $\begin{array}{l}\text { Biyo yakıt ve } \\
\text { diğer }\end{array}$ & $\begin{array}{l}\text { Biyo yakıt bazlı elektrik üretiminde ekonomik erişilebilir kapasitenin } \\
\text { Türkiye yenilenebilir enerji strateji belgesi ile uyumlu olacağı varsayılmıştır, } \\
\text { diğerlerinde model maliyet azaltımı amacı güderek kaynak kullanımı } \\
\text { yapacaktır. }\end{array}$ \\
\hline $\begin{array}{l}\text { Elektrik } \\
\text { İletim ve } \\
\text { Dağıtımı }\end{array}$ & \multicolumn{2}{|c|}{ Kayıp-kaçak oranı \%17 olarak sabit alınmıştır. } \\
\hline $\begin{array}{l}\text { Ulaştırma } \\
\text { Sektörü }\end{array}$ & \multicolumn{2}{|c|}{$\begin{array}{l}\text { Model maliyet azaltımı amacı güderek kaynak kullanımı yapacaktır. Emisyon azaltımına } \\
\text { yönelik herhangi bir politika veya uygulama öngörülmemektedir. }\end{array}$} \\
\hline $\begin{array}{l}\text { Endüstri } \\
\text { Sektörü }\end{array}$ & \multicolumn{2}{|c|}{$\begin{array}{l}\text { Model maliyet azaltımı amacı güderek kaynak kullanımı yapacaktır. Emisyon azaltımına } \\
\text { yönelik herhangi bir politika veya uygulama öngörülmemektedir. }\end{array}$} \\
\hline $\begin{array}{l}\text { Konut ve } \\
\text { Hizmet } \\
\text { Sektörleri }\end{array}$ & \multicolumn{2}{|c|}{$\begin{array}{l}\text { Mevcut binalarda yalıtım kaynaklı enerji tasarrufu olmadığı varsayılmıştır. Emisyon } \\
\text { azaltımına yönelik herhangi bir politika veya uygulama öngörülmemektedir. Yeni binaların } \\
\text { yönetmeliklere uygun inşa edileceği varsayılmıştır. }\end{array}$} \\
\hline $\begin{array}{l}\text { Tarım } \\
\text { Sektörü }\end{array}$ & \multicolumn{2}{|c|}{$\begin{array}{l}\text { Model maliyet azaltımı amacı güderek kaynak kullanımı yapacaktır. Emisyon azaltımına } \\
\text { yönelik herhangi bir politika veya uygulama öngörülmemektedir. }\end{array}$} \\
\hline
\end{tabular}

Model veritabanı başta Türkiye İstatistik Kurumu verileri olmak üzere Bakanlıkların ve sektörel sanayici derneklerinin raporları kullanılarak tümüyle kamuya açık verilerden oluşturulmuştur.

\section{Sonuçlar}

Sonuçlar iki ana başlık altında incelenmektedir. İlk olarak referans senaryoya ait değerler verilirken, daha sonra emisyon vergisine sistemin verdiği tepkiyi açıklamak adına emisyon vergisi senaryo analizlerine ait sonuçlar sunulmaktadır. 


\section{Referans Senaryo Sonuçları}

Türkiye enerji tüketimine ait değerler sektörel bazda ele alınmaktadır. Her bir sektör için referans senaryo içerisinde aldıkları değerler ile emisyon fiyatlandırması senaryoları altında nasıl değişiklik gösterdiklerine dair açıklamalar yer almaktadır. Her bir sektöre ait enerji tüketimleri ve teknoloji kullanım detayları aşağıdaki gibidir:

\section{Tarım Sektörü}

Tarım sektörünün temel tüketimini dizel oluşturmaktadır. Dizel tüketiminin yıllar içerisinde artarak 2052 yılında yaklaşık 130PJ'ye erişmesi beklenmektedir. Diğer bir önemli enerji kaynağını ise sulama ve seracılık işlemlerinde kullanılmak üzere elektrik oluşturmaktadır. Elektrik talebinin 2012 yılında gerçekleşen tüketimin yaklaşık 3.5 katına çıkması öngörülmektedir. Diğer yakıt tüketimlerine ait değişim Şekil 3’te görüldügü gibidir.

Şekil 3 Tarım Sektörü Referans Senaryo Enerji Tüketimleri

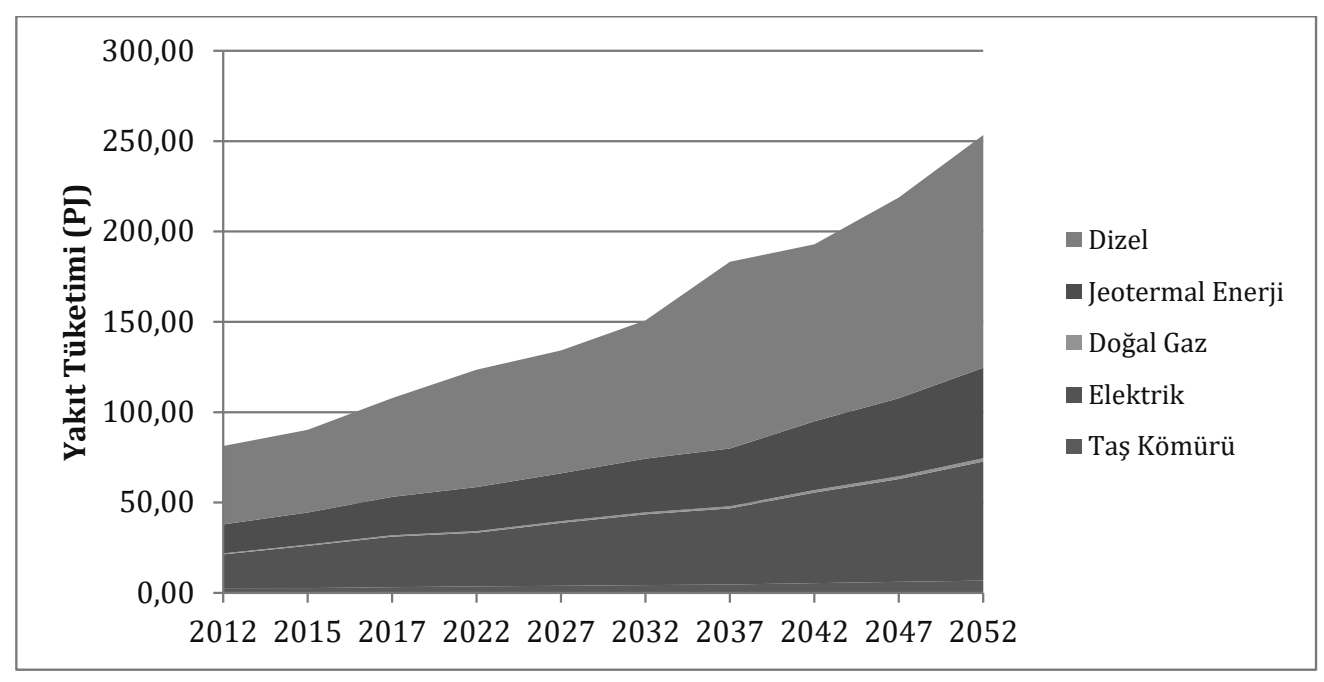

\section{Endüstri Sektörü}

Endüstri sektörü içerisinde; Demir Çelik, Çimento, Kâğıt alt-sektörleri gibi yoğun enerji tüketimi olan dokuz farklı alt-sektör (Birincil Demir Çelik, İkincil Demir Çelik, Demir Dışı Metaller, Gıda, Çimento, Kâğıt, Kimya, Cam ve Seramik sektörleri) ayrı ayrı ele alınmıs, diğer alt-sektörler (enerji genel denge tablosundaki "diğer sektörler" tanımına paralel olarak) toplu halde modele yansıtılmıştır. Alt-sektörlere ait enerji tüketimi projeksiyonları, Dünya Bankası́nda Türkiye için yapılmış olan GSYİH projeksiyonu ile eş büyüyeceği kabulü ile oluşturulmuştur. Endüstri sektörünün senaryo bazında toplam yakıt tüketimleri Şekil 4’te sunulmaktadır. Referans senaryo incelendiğinde, 2052 yılı itibariyle, endüstri sektörü toplam enerji talebinin baz yıla göre yaklaşık 2000PJ artış gösterdiği gözlenmektedir. Sektöre ait en çok tüketilen enerji kaynakları olan taş kömürü doğalgaz ve elektriktir. 2012 yılında 330PJ olan elektrik talebinin, 2052 itibariyle yaklaşık 700PJ’a ulaşması öngörülmektedir. Baz yılında yaklaşık 395PJ olan kömür talebinin ise, 2052 itibariyle Referans Senaryoda 998PJ’a ulaşması, model içerisinde emisyon maliyetlerinin aktive edildiği senaryolarda ise bu değerin oldukça düşerek, yerini elektrik tüketimine bırakacağı öngörülmektedir. Bu durumda 2052 elektrik talebinin 1428PJ olması öngörülür. 
Şekil 4 Endüstri Sektörü Referans Senaryo Enerji Tüketimleri

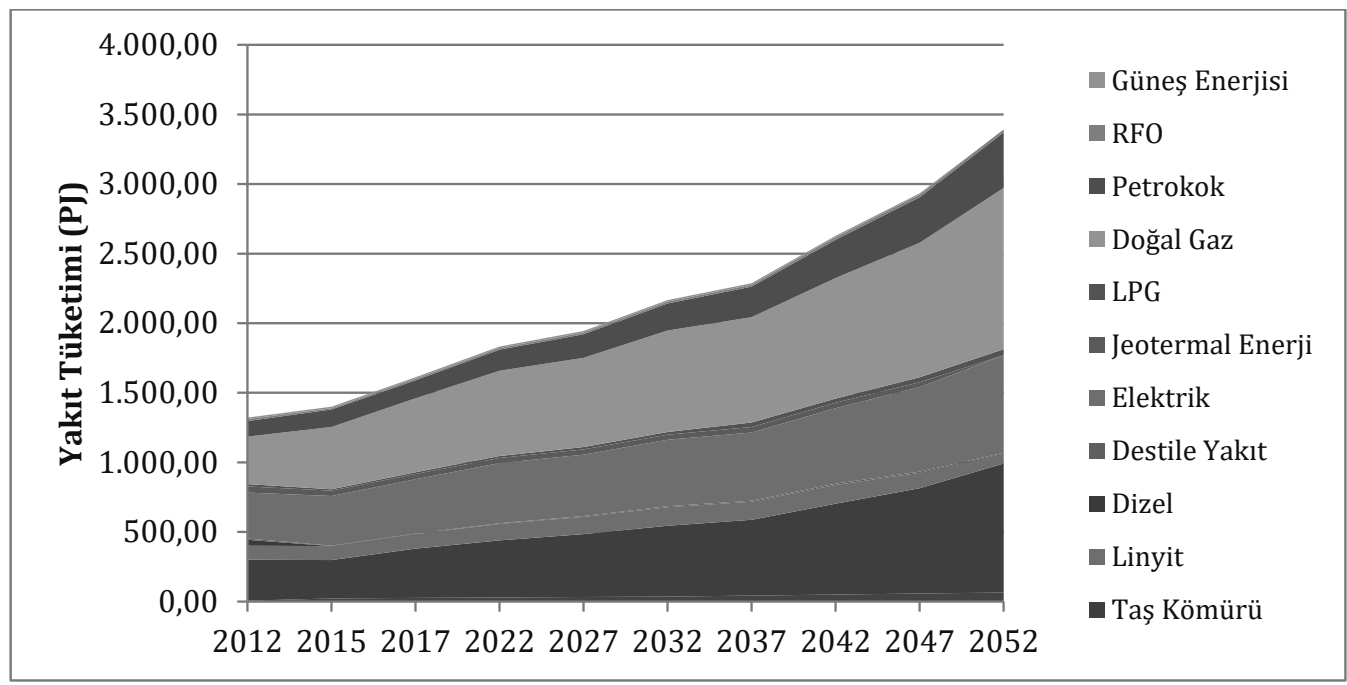

\section{Konut ve Hizmet Sektörü}

Konut ve hizmet sektörü için öngörülen yakıt tüketimine ait projeksiyon Şekil 5'te verilmektedir. Referans senaryoda, 2012 itibariyle, yaklaşı 1.370 PJ'lik enerji tüketimine sahip olan konut ve hizmet sektörünün 2052 itibariyle 3.728 PJ'lik talebe ulaşması öngörülmektedir. Baz yılı doğalgaz talebi sektörün toplam tüketiminin \%27'sini karşılarken, bu değerin analiz dönemi sonunda \%31'e çıkması beklenmektedir. Konutlardaki elektrik talebinin ise, modelleme dönemi sonunda, 955PJ'a çıkarak mevcut talebin iki katına çıkması öngörülmektedir. Elektrik tüketimi 2012 yılında toplam tüketimin yaklaşık \%30'unu karşılarken, bu değerin 2052 itibariyle \%26'ya düşmesi, enerji verimli teknolojilerin ve isı yalıtım sistemlerinin model içerisinde devreye alındığının bir göstergesidir.

Şekil 5 Konut ve Hizmet Sektörü Referans Senaryo Enerji Tüketimleri

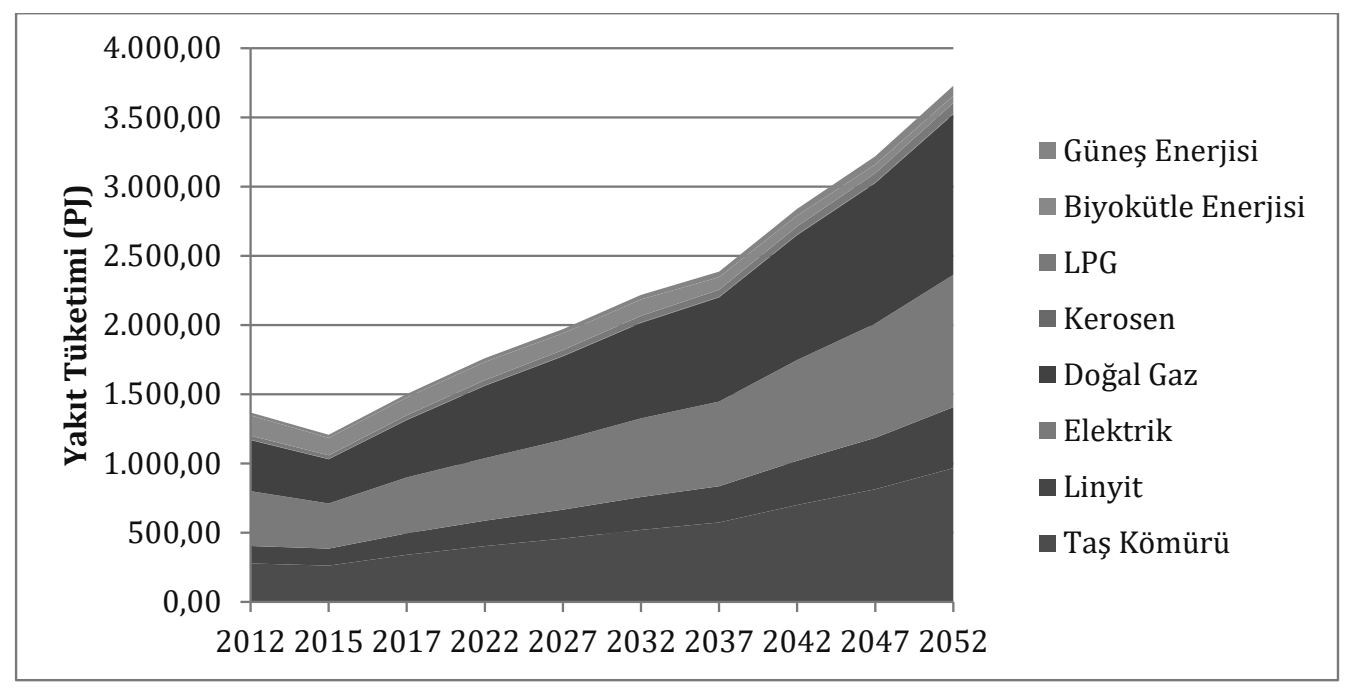




\section{Ulaştırma Sektörü}

Ulaştırma sektörü enerji talebi, her bir ulaşım tipi (havayolu, karayolu, denizyolu ve demiryolu) için baz yıl yakıt tüketimlerini karşılayacak araç stoğu ve kullanım talebinin model içerisinde tanımlanması ile modellenmiştir. Ulaştırma sektörü için öngörülen yakıt tüketimine ait projeksiyon Şekil 6 'da verilmektedir.

Şekil 6 Ulaştırma Sektörü Referans Senaryo Enerji Tüketimleri

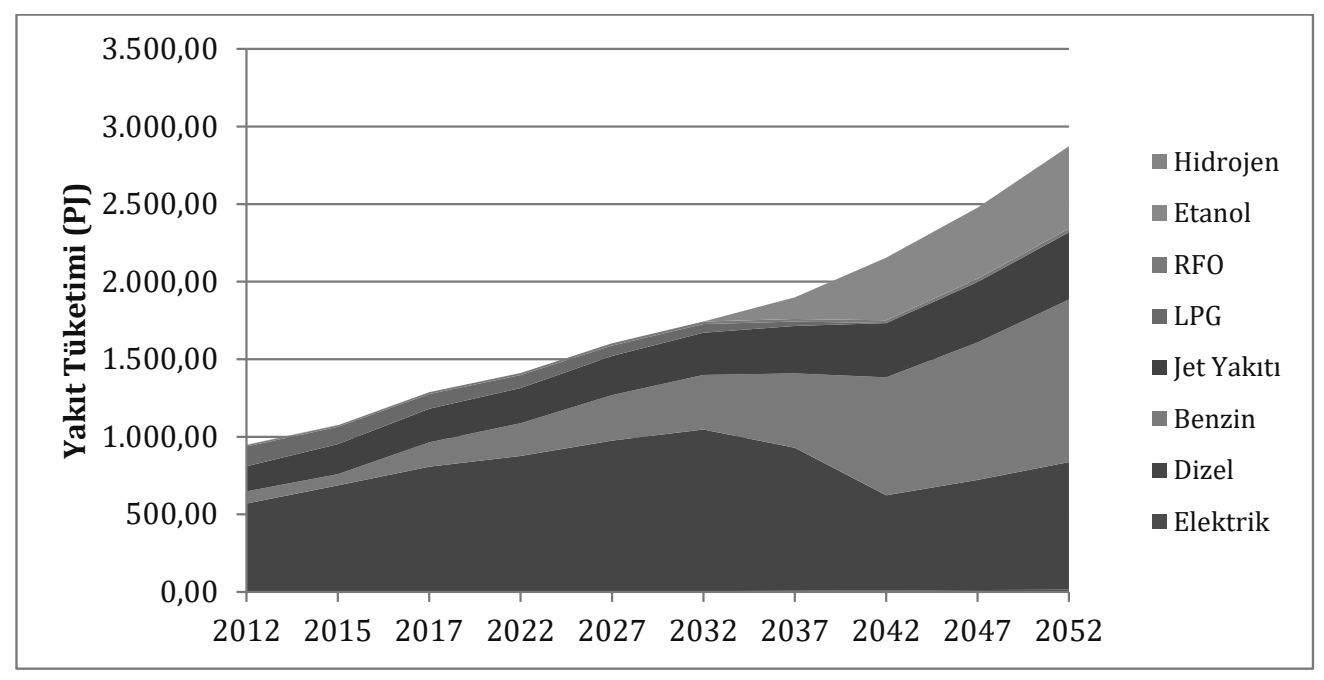

Yakıt oranları incelendiğinde, 2012 yılı dizel tüketim oranının \%60 ile en büyük pay sahibi olduğu gözlenmektedir. Yakıt kullanım oranlarının 2052 yılındaki değerleri incelendiğinde dizelin 822PJ’a çıkacağı gözlenmektedir. Benzin tüketim değerleri incelendiğinde toplam enerji tüketimi içerisindeki payının artarak \%24'e erişeceği gözlenmektedir.

\section{Elektrik Üretimi Sektörü}

Şekil 7 Elektrik Üretimi Sektörü Referans Senaryo Enerji Tüketimleri

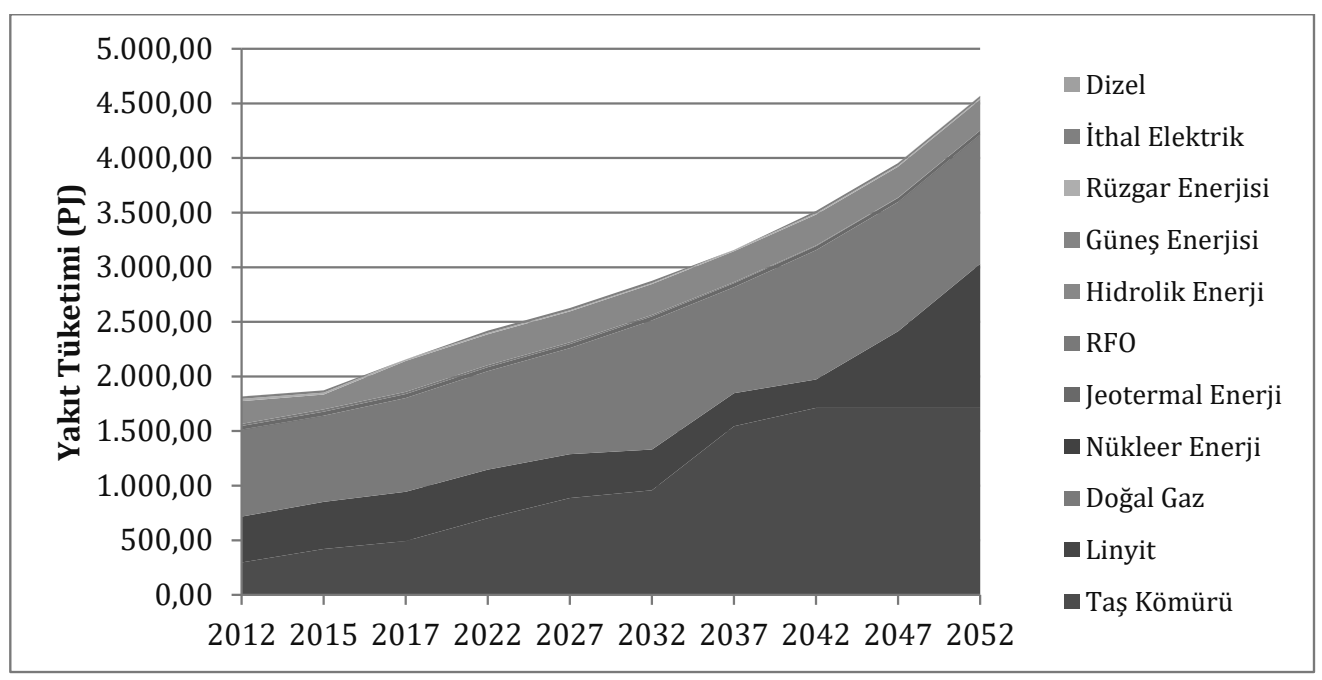


Referans senaryo içerisinde elektrik üretim sektörü için öngörülen yakıt tüketimine ait projeksiyon Şekil 7'de verilmektedir. 2012 itibariyle referans senaryosunda yaklaşık 1817PJ'lik enerji tüketimine elektrik üretimi sektörünün 2052 itibariyle 4568 PJ'lik talebe ulaşması öngörülmektedir ve doğalgaz talebinin azalarak sektörün toplam tüketimin \%26’sını karşılaması beklenir. Senaryolar sonucunda elde edilen bir diğer bulgu ise emisyon fiyatı arttıkça yerel elektrik üretiminin artmasıdır. 10 'llk emisyon fiyatlandırmasında üretim değeri 2052 yılı için 4658PJ'den 5792PJ'a 20\$'lıkve 30\$'lık fiyat altında ise 6746PJ'a çıması öngörülmektedir. Bu da Türkiye toplam emisyon azaltımının emisyon fiyatlandırması altında beklenenden düşük seyretmesine neden olmaktadır. Nihai yakıt tüketimlerine ait emisyon diğer sektörlerde fosil yakıtlar yerine elektrik tüketimindeki artış ile azalıyorken, elektrik üretimi artacağından bu sektör için aksi durum söz konusu olacaktır.

\section{Emisyonlar}

Türkiye içerisinde daha öncede belirtilmiş olan beş ana sektöre ait sera gazı salım değerlerine ait öngörüler Şekil 8'de gösterilmiştir. 2012 yılında gerçekleşen salım değeri rafineri faaliyetleri kaynaklı emisyonlar ile proses emisyonları da eklendiğinde yaklaşı 400 Mton $\mathrm{CO}_{2}$ iken bu değerin 2052 yılı itibariyle 1540 Mton $\mathrm{CO}_{2}$ 'ya erişmesi beklenmektedir. Sektörler bazında emisyon performansları incelendiğinde en yüksek salım değerinin enerji sektörüne ait olduğu gözlenir. Baz yılı içerisinde tüm salım değerinin \%36'sını enerji, sektörü oluşturmaktayken bu değer analiz dönemi boyunca kadar artış göstermekte ve 2052 yılında \%42'ye ulaşmaktadır.

Tarım sektörü toplam içerisinde en az salım değerine sahiptir. 2052 yılı tarımsal faaliyetlerden kaynaklı salım değeri 11 Mton $\mathrm{CO}_{2}$ 'ya ulaşmaktadır. Ortalama verim değerindeki iyileşme \%14 düzeyinde seyretmektedir.

Emisyon değerleri incelendiğinde 2012 yılında toplam emisyonun \%18'ini (64 Mton $\mathrm{CO}_{2}$ ) konut ve hizmet sektörü oluşturuyorken bu değer analiz dönemi sonunda \%16'ya (239 Mton $\mathrm{CO}_{2}$ ) gerilemektedir. Toplam salım değerinde bir artış gözlenmesine rağmen yüzdesel oradan toplam salım içerisindeki payının azalması tükettiği yakıt sepetinin değişerek, doğalgaz ve elektrik tüketiminin daha yoğun kullanılmasından kaynaklanmakta dolayısı ile bu sektör için artıştan azalım sağlanmaktadır. Aynı durum ulaştırma sektörü için de söz konusudur. Baz yılında toplam salım değerinin \%19'u ulaştırma sektörü kaynaklı iken bu değer 2052 yılında \%13'e gerilemektedir. Ortalama taşıt teknolojisine ait verim düzeyinde 2032 yılına kadar \%29,6'lık iyileştirme öngörülmekteyken bu değerin 2052 yılında \%37.03 olması beklenmektedir. Ortalama emisyon değerindeki düşüşün referans senaryo için yakıt sepetindeki değişimden çok araç enerji tüketimindeki iyileşmeden kaynaklandığı görülür. 
Şekil 8 Referans Senaryo Sera Gazı Salım Değerleri (Proses emisyonları hariç)

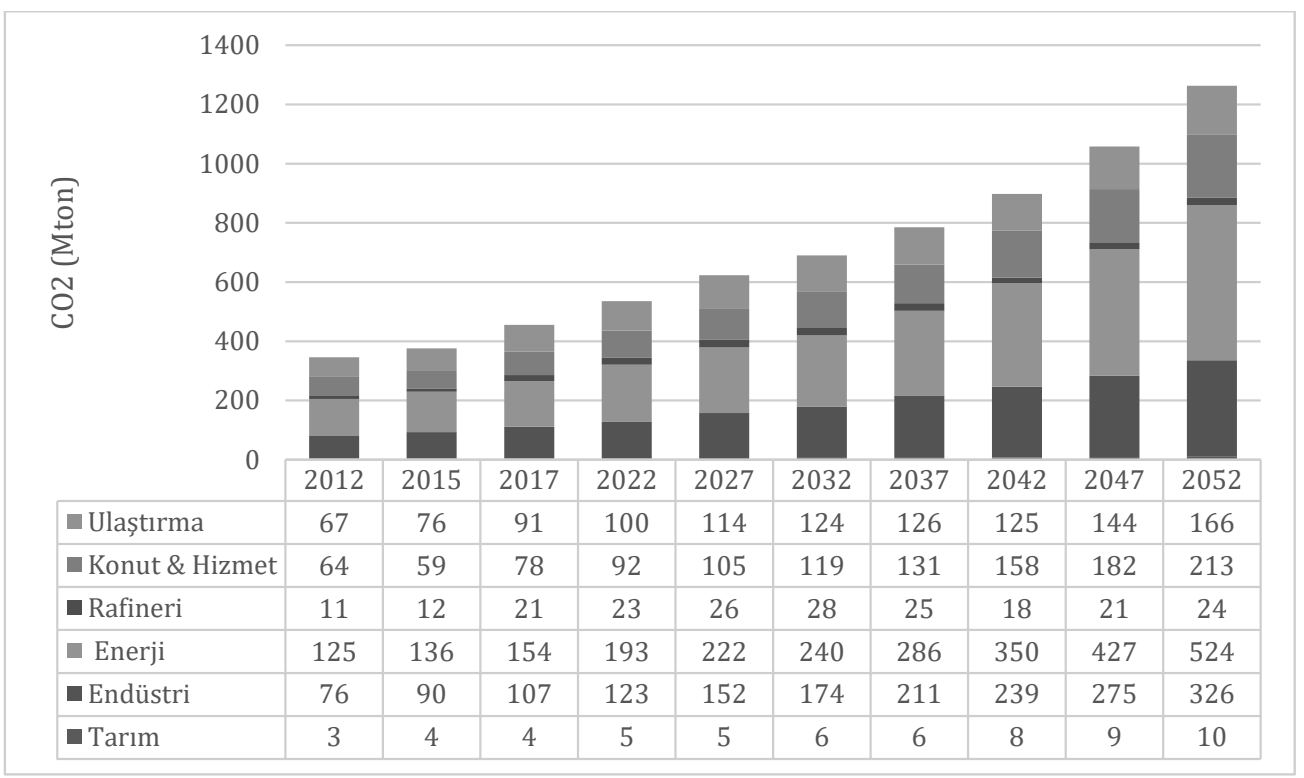

\section{Azaltım Politikaları}

Şekil 9'da belirtildiği gibi sera gazı emisyonlarını azaltmak için kullanılacak politikalar ekonomik ve mali araçları içerdiği gibi, sektör paydaşları tarafından düzenlenen gönüllü anlaşmalar ve enerji tasarrufu konusunda halkı bilinçlendirmeye yarayacak farkındalık programlarının düzenlenmesine kadar geniş bir yelpazeyi içermektedir.

Ekonomikve mali araçlar piyasa temellive piyasa dışı temelli olarakiki ana sınıfta incelemektedir. Piyasa temelli karbon ticaretine ait farklı uygulama türleri mevcuttur. Ticari izinlere ait zemin, emisyonlara ait en yüksek tüketim limitlerinin belirlenmesi böylelikle belirli seviyede emisyon salımı için izin verilmesi kavramı ile ortaya çıkmıştı. Sonrasında ise izin verilen karbon seviyelerinin belirli ölçüde satışının verimli bir politika aracı olarak kabulü ile kullanılmaya başlanmıştır. ${ }^{43}$

Şekil 9 Emisyon Azaltımı Politika Araçları

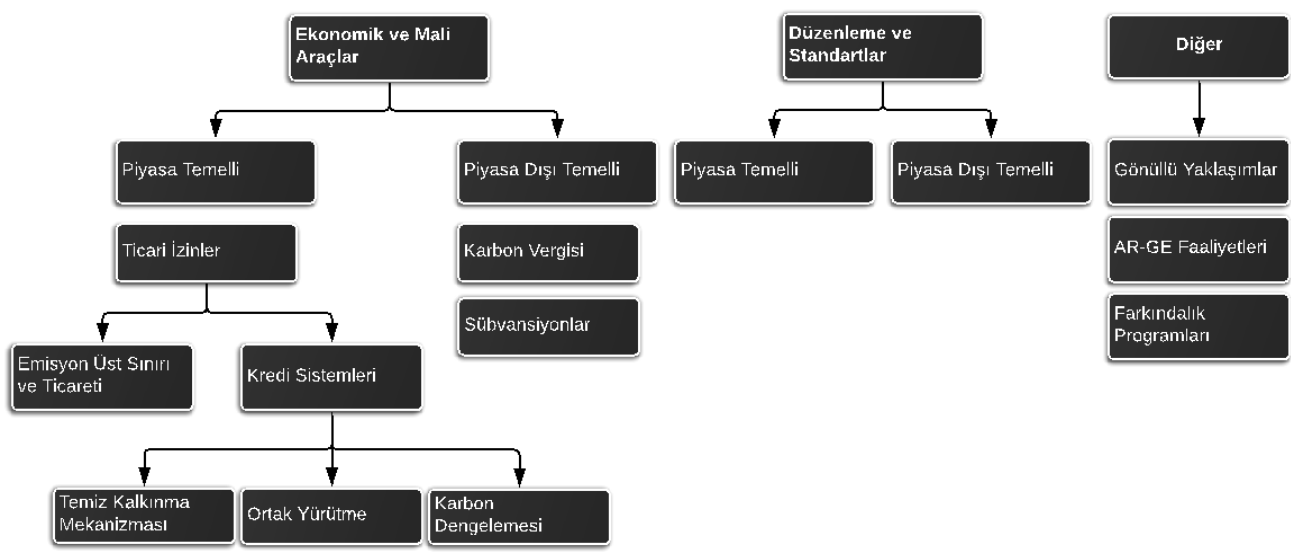

43 W. David Montgomery, "Markets In Licences and Efficient Pollution Control Programs”, Journal of Economic Theory, Cilt 5, 1972, s.395-418. 
Küresel ısınmaya ve karbon emisyonlarına karşı kontrol mekanizmalarının en önemlilerinden biri olan Kyoto Protokolü 1997 yılında emisyon üst sınırı ve ticaret sistemini uluslararası düzeyde düzenlemeyi amaçlamaktadır. ${ }^{44}$ Sonrasında ise 2005 yılında duyurulan Avrupa Birliği Emisyon Ticareti Sistemi (EU-ETS) ile günümüzdeki en büyük karbon ticareti piyasası kurularak iklim değişikliği ile mücadele için önemli bir adım daha atılmıştır.

Emisyon üst sinırı ve ticareti sistemleri (cap and trade systems) ile kredi sistemleri (emission reduction credit systems) ticari izinleri oluşturan iki temel politika aracıdır. ${ }^{45} \mathrm{Bu}$ iki politika aracı da temelinde, ekolojik olarak sürdürülebilir düzeyde emisyon salımına izin vererek, emisyon salımı için üst sınır koymakta bu sınırlara ait izinlerin ticari bir araç gibi alınıp satılmasına olanak tanımakta ve böylelikle emisyon artışını belirli bir düzeyde tutmayı amaçlamaktadır.

Diğer bir Ticari İzin Sistemi olan Kredi sistemleri ise Temiz Kalkınma Mekanizması (CDM) , Ortak Yürütme Programları ve Karbon Dengelemesi’nden oluşan üç ana başlığı içermektedir.32 Emisyon ticaretine ait politika araçları (Karbon Dengelemesi hariç) Kyoto Protokolü çerçevesinde düzenlenmektedir.

CDM ile EK-I ülkeleri, gelişmekte olan ülkelere kendi gelişmiş teknolojileri transfer edecekleri projeleri gerçekleştirdikleri taktirde, hem Ekler Dışı ülkelerde de emisyon azaltımına destek vermiş olacak hem de Sertifikalanmış Emisyon Azaltım Kredisi (Certification Emissions Reduction-CER) kazanarak, toplam emisyon azaltım taahhütlerinden bu değeri düşebileceklerdir. ${ }^{46}$

Kyoto Protokolü ile düzenlenen diğer bir proje temelli esnek emisyon azaltım yöntemi ise Ortak Yürütme (OY_JI) programlarıdır. OY ile iki farklı EK-I ülkesi arasında gerçekleştirilecek projesi ile emisyon azaltımı sağlandığı takdirde Salım Azaltma Kredisi (Emission Reduction Unit-ERU) kazanabilmektedir. ${ }^{47}$

Karbon Dengeleme ise gönüllülük esasına dayanmaktadır. Herhangi bir firma faaliyetleri sonucu açığa çıkan sera gazı salımlarını hesaplayarak, toplam ayak izlerini kadar emisyon tasarrufu sağlayacak başka bir projeye yatıım yapmakta ve/veya bu değere eş karbon sertifikası satın almaktadırlar.

Piyasa temelli politika araçlarının yanında emisyon azaltımı için AR-GE faaliyetlerinin geliştirilmesi, gönüllü kuruluş faaliyetleri ve düzenlenen eğitimler ile halkı bilinçlendirme gibi opsiyonların yanı sıra doğrudan devlet tarafından piyasaya sunulan vergi ve sübvansiyon gibi araçlar da kullanılmaktadır.

Karbon vergisi emisyon hacmini azaltıcı politika aracı olarak birçok ülke tarafından uygulanmaktadır. Kısaca özetlemek gerekirse fosil yakıtların tüketilmesi sonucunda ortaya çıkan karbon emisyonları üzerine tanımlanmış bir vergi olarak adlandırılabilmektedir. ${ }^{48}$ Karbon vergisindeki amaç temiz teknoloji ve yakıt opsiyonlarını teşvik etmek, fosil kaynak tüketimini ve bundan doğan

44 Bin Zhang ve Liang Xu, "Multi-item Production Planning With Carbon Cap and Trade Mechanism” International Journal of Production Economics, Cilt 144, 2013, s.118-127.

45 Hüseyin G. Çiçek ve Serdar Çiçek, “Karbon Vergisi İle Karbon Ticareti İzinlerinin Karşılaştırılması” İ.Ü. Siyasal Bilgiler Fakültesi Dergisi, Cilt 47, 2012, s.95-119.

46 Etem Karakaya, Küresel Isınma ve Kyoto Protokolü İklim Değişikliğinin Bilimsel, Ekonomik ve Politik Analizi, İstanbul, Bağlam Yayıncılık, 2008, s.169-196.

47 Michèle Bretona et.al., "A Differential Game of Joint Implementation of Environmental Projects” EJOR, Cilt 41, 2005, s.1737-1749.

48 Marc N. Conte ve Matthew J. Kotchen, "Explaining The Price of Voluntary Carbon Offsets", National Bureau of Economic Research (NBER), Cilt.15294, 2009, s.1. 
negatif dışsallığı azaltmaktır. Karbon vergisi ilk olarak Finlandiya’da (1990) sonrasında ise İskandinav ülkeleri (Hollanda-1990, Norveç-1991, İsveç-1991 vb.) tarafından uygulamaya sokulmuştur (1). Ton başına emisyon vergisi ülkelere göre oldukça farklılık göstermekte 15.93 dolardan ( Norveç) 104.83 dolara (İsveç) kadar geniş bir yelpazede dalgalanmaktadır. ${ }^{49} \mathrm{Bu}$ çalışma kapsamında Türkiye için hangi emisyon değerinin daha verimli olduğunu gözlemlemek adına senaryo analizleri gerçekleştirilmiştir.

\section{Karbon Vergisi Senaryoları}

Bu kısım, sistem içerisine emisyon vergisi tanımlandığında sektörel bazda yakıt tüketimleri ile enerji sektörü ve talep sektörlerine ait teknoloji yatırımlarının nasıl şekillendiğini göstermektedir. " $\mathrm{CO} 2$ 10, CO2-20, CO2-30” olmak üzere emisyon maliyetinin ton başına $10 \$, 20 \$$ ve 30 \$ oluğu kabulü ile çalışan üç farklı senaryoya ait sonuçlar her bir sektör için açıklanmaktadır.

\section{Tarım Sektörü}

Tarım sektörüne ait teknoloji düzeyinde detay bilgi bulunamadığından model içerisine doğrudan yakıt tüketimleri tanımlanmıştır. Yakıt değişimlerini emisyon vergisi kısıtları altında izlemek mümkün olmadığından bu sektör için önemli düzeyde değişim gözlenememiştir.

\section{Endüstri Sektörü}

Endüstri sektörü içerisinde kömür türevlerinin (taş kömürü, linyit ve asfaltit) toplam enerji tüketimi içerisindeki payı yaklaşık \%21 iken bu oran emisyon vergisi tanımlandığında \%5’e kadar gerilemektedir. Sektörün kömürden karşıladığı enerjiyi doğal gaz ve elektrik ile ikame etmektedir. BAU senaryosunda 2012-2052 yılları içerisinde toplam elektrik tüketiminin 7622PJ olması bekleniyorken bu değer; CO210 senaryosunda 7704PJ, CO2-20 senaryosunda 7710PJ ve CO2-30 senaryosunda 7717PJ değerine ulaşmaktadır. Doğala gaz içinde aynı durum söz konusudur. Emisyon vergisi ile doğru orantılı olarak tüketim değerin 14270PJ ile 15715PJ arasında değiştiği gözlenir. LPG tüketiminde ise ters orantı gözlenir. BAU senaryosunda 2052 yılında 81 PJ’a erişmesi beklenen LPG tüketimi her üç senaryo içinde 50PJ değerine gerilemektedir.

\section{Konut ve Hizmet Sektörü}

BAU senaryosu koşulları altında, konut ve hizmet sektörüne ait sera gazı salım değerinin 20122052 yılları içerisinde toplam 1190 Mton $\mathrm{CO}_{2}$ olması bekleniyorken bu değer CO2-10 senaryosu için 910 Mton CO2'ya gerilemektedir. Bu sektör, emisyon vergisi ile yaklaşı $280 \mathrm{Mton} \mathrm{CO}_{2}$ azaltım potansiyeline sahiptir. Bu değerin 10 \$, 20\$ ve 30 \$ seviyelerinden etkilenmediği gözlenir. Bu azaltımı LPG ve ısınma amaçlı kömür tüketimini azaltarak gerçekleştirir yerine doğal gaz tüketiminde artış gözlenmektedir. Modelin elverişli solar kapasitesinin tamamını BAU senaryosunda kullandığı ve diğer senaryolarda da en üst düzeyde tuttuğu gözlenir. Bu durum konut ve hizmet sistemine yapılacak teşvikler ve altyapı çalışmaları ile desteklendiği takdirde olası potansiyelin arttırılması halinde çok daha yüksek düzeyde emisyon azaltımı sağlayacağının bir göstergesidir. Elektrik tüketiminin değişmemesi ise, verimli teknolojiye teşvik verilmediği durumda mevcut teknoloji sepetinin senaryodan bağımsız olarak 2052 sonuna kadar devam edeceğini gösterir.

49 Jenny Sumner et.al., "Carbon Taxes: A Review of Experience and Policy Design Considerations”, Colorado, National Renewable Energy Laboratory, 2009, s.11. 


\section{Ulaştırma Sektörü}

Ulaştırma sektörü senaryolara göre teknoloji seçimini şekillendirmiş, vergiden etkilenmiştir. Model ulaştırma sektörü için emisyon düzeyi arttıkça enerji verimi yüksek teknolojilere geçiş yaparak CO2-10 için ortalama verim artışı \%12.15, CO2-20 için ortalama verim artışı \%24.09, CO2-10 için ortalama verim artışı \%24.16 olarak gözlenmektedir. Değişimler yakıt bazında incelendiğinde, BAU senaryosuna ait 2012-2052 yılındaki tüm yakıt değerleri incelendiğine toplam tüketimin \%56'sını dizel oluşturuyorken bu değer, 10 \$'lık emisyon tanımlandığında \%46'ya, 20\$'lık emisyon tanımlandığında \%36'ya ve 30\$'lık emisyon tanımlandığında ise \%33'e gerilemektedir. CO2-10 ve CO2-20 senaryoları altında hidrojenle çalışan araçların 2022 yılında 5.19PJ'lik tüketimle devreye girdiği bu değerin CO2-30 senaryosunda 20.12PJ'ye çıktığı ve her bir senaryoda giderek artarak 456PJ'ye ulaştığı gözlenmektedir.

\section{Elektrik Üretimi Sektörü}

Elektrik üretimi sektörü içerisinde kullanılan teknolojilerde, emisyon vergisi senaryoları altında (vergi tutarından bağımsız olarak) ortalama \%9.37’lik verim artışı gözlenmektedir. Referans senaryoda güneş enerjisinden elektrik üretimi oldukça düşüktür. BAU senaryosunda bu değer oldukça düşük seviyedeyken seyrediyorken, emisyon vergisi senaryoları altında 2022 itibariyle 35.73PJ, 2032 itibariyle 46.44PJ'lik elektriğin güneş enerjisinden üretildiği görülür. BAU, CO2-10 ve CO2-20 senaryolarından nükleer enerji elektrik üretimi için kullanılmıyorken, emisyon vergisi $30 \$$ seviyesine eriştiğinde emisyon azaltımı için model nükleer santral kurulumuna karar vermektedir. Rüzgar enerjisinden elektrik üretiminin ise emisyon vergisinden etkilenmediği, BAU senaryosundaki üretim seviyelerinde seyrettiği gözlenir. Bu durum BAU senaryosu koşulları altında rüzgâr enerjisine ait olası en yüksek üretimin hali hazırda gerçekleştiğini göstermektedir. Hidrolik enerji ise 2017 itibariyle dönemsel teknik kapasitenin en üst seviyesine erişmiş ve 2052 yılına kadar aynı kapasite ile elektrik üretimine katkı sağlamıştır. Kömür tüketimi incelendiğinde ancak 30\$’lık emisyon vergisi altında azalım gözlenmektedir. BAU senaryosu altında 2032 itibariyle 446.32PJ olması beklenen taş kömürü tüketimi CO2-30 senaryosunda 301.38PJ'a gerilemektedir. Linyit tüketiminde ise emisyon vergisine oldukça yüksek yanıt verdiği gözlenmektedir. BAU senaryosu altında 2052 itibariyle toplam 1295PJ'lik elektrik üretiminin linyitten karşılanacağı gözleniyorken bu değer CO2-10 ve CO2-20 senaryolarında 1032PJ, CO2-30 senaryosunda ise 895PJ'a gerilemektedir.

\section{Emisyonlar}

Emisyon vergisi kısıtları altında çalıştırılan üç senaryo ile referans senaryoya ait emisyon projeksiyonları Şekil 9'da belirtilmektedir. Bu değerler incelendiğinde sistemin emisyon vergisi ile yapacağı değişikliklerin sınırlı olduğu görülmektedir. Genel itibariyle sistemin asıl tepkisi CO210 senaryosu altında şekilleniyorken CO2-20 ve CO2-30 senaryolarında anlamlı düzeyde bir fark gözlenmemektedir.

Sektörlerin verdiği tepkiler incelendiğinde Tarım sektöründeki toplam emisyon değişiminin yaklaşık 9 Mton $\mathrm{CO}_{2}$ olduğu gözlenir. Ulaştırma sektörü ise BAU senaryosuna göre toplam emisyon değerinde 248 Mton $\mathrm{CO}_{2}^{\prime}$ luk azaltım sağlamıştır. CO2-10 senaryosundaki toplam emisyon azaltımındaki toplam kazancın sektörlere göre dağılımı incelendiğinde ise \%59 ile elektrik üretimi sektörünün en yüksek katkıyı sağladığı onu \%21'lik emisyon azaltımı ile endüstri sektörünün takip ettiği görülür. 
Şekil 10 Emisyon Senaryoları Sera Gazı Salım Değerleri

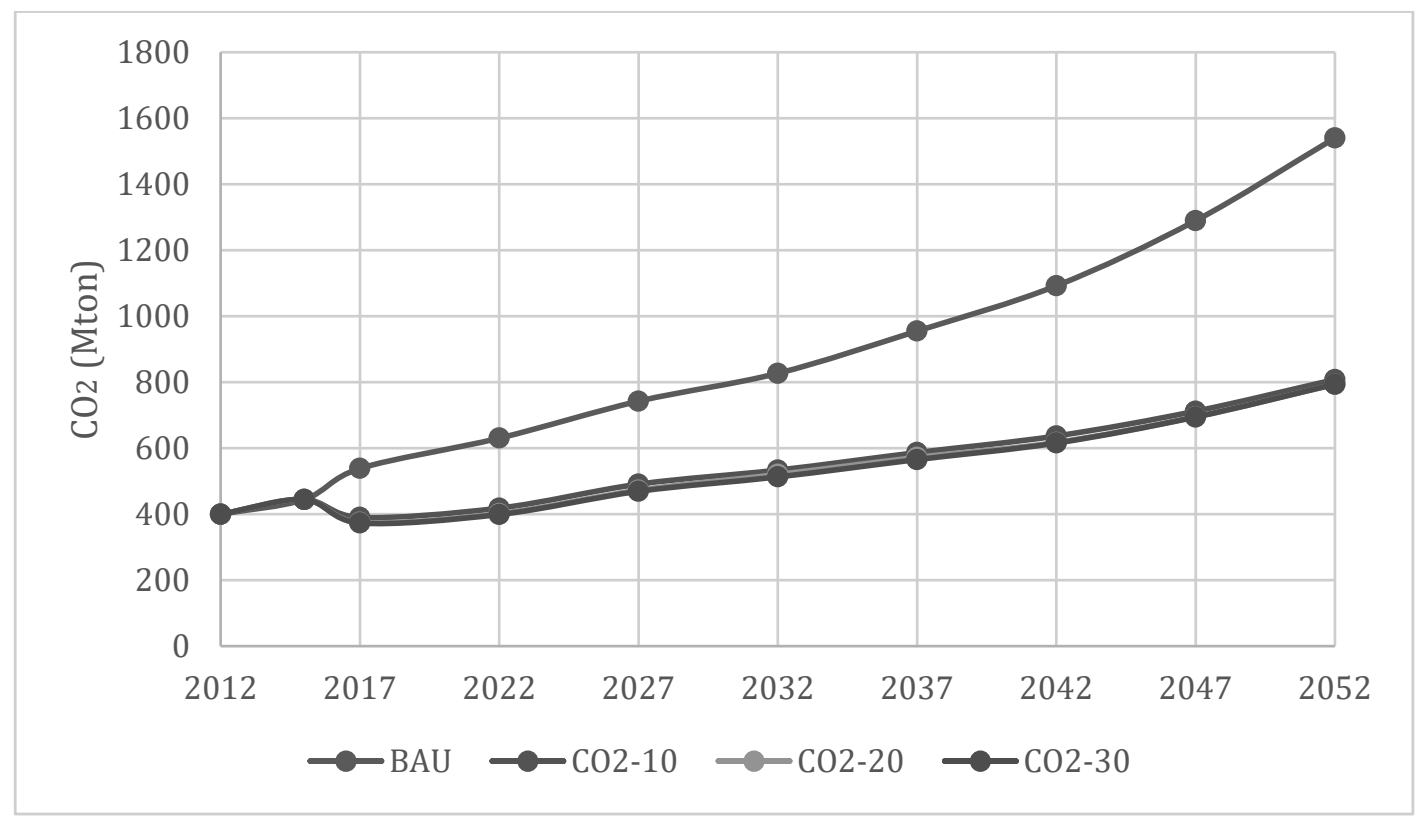

\section{Maliyetler}

Model içerisinde maliyetler dört ana başlık altında incelenmektedir. Bunlardan, yatırım maliyetleri, sabit operasyonel giderler ve aktivite maliyetleri teknolojiler için gerçekleşen giderler iken akış maliyetleri yakıtların tüketiminden kaynaklanan maliyetlerdir.

Maliyetlerin senaryolar altında nasıl değişiklik gösterdiğine dair bilgi Tablo 3'de verilmektedir. En büyük farkın aktivite ve yatırım maliyetlerinde gerçekleştiği gözlemlenmektedir. Yatırım maliyetlerindeki toplam artış CO2-10, CO2-20 ve CO2-30 senaryoları için sırası ile \%5, \%10 ve \%14'tür. Maliyet artışındaki yüzdesel değişim oranında emisyon azaltımı gerçekleşmemektedir. Maliyet etkin ve yüksek azaltım potansiyeli olan teknolojilerin C02-10 senaryosunda devreye girdiği, diğer senaryolarda ise çok yüksek maliyetli ve düşük emisyon azaltımı olan teknolojilerin devreye alımı söz konusu olmuştur.

Yakıt tüketimi maliyetlerinde ise referans senaryo değerlerine göre azalma izlenir. Bunun nedeni olarak yenilenebilir kaynağa geçiş ile petrol türevi kaynaklar ile yakıt ithalatındaki azalma gösterilebilir.

$\mathrm{Bu}$ çalışma kapsamında sadece referans senaryo ile 2052 yılına kadar Türkiye Enerji Sektörü’ne ait öngörüler ortaya konmamış bununla birlikte emisyon vergisine hem tüketim sektörleri hem de elektrik üretimi sektörüne ait tepkiler analiz edilmiştir. 


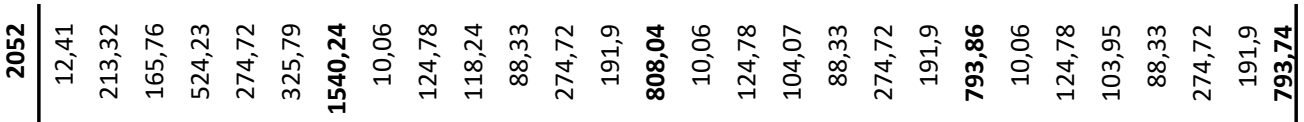

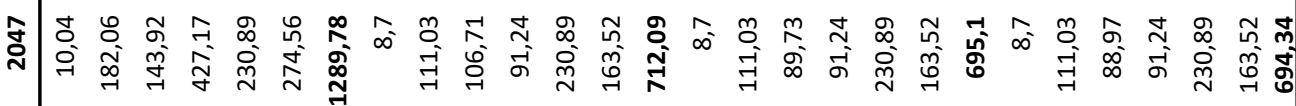

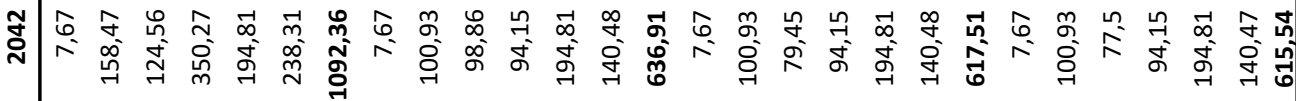

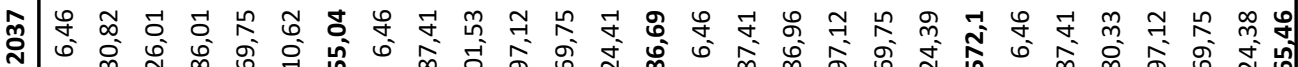

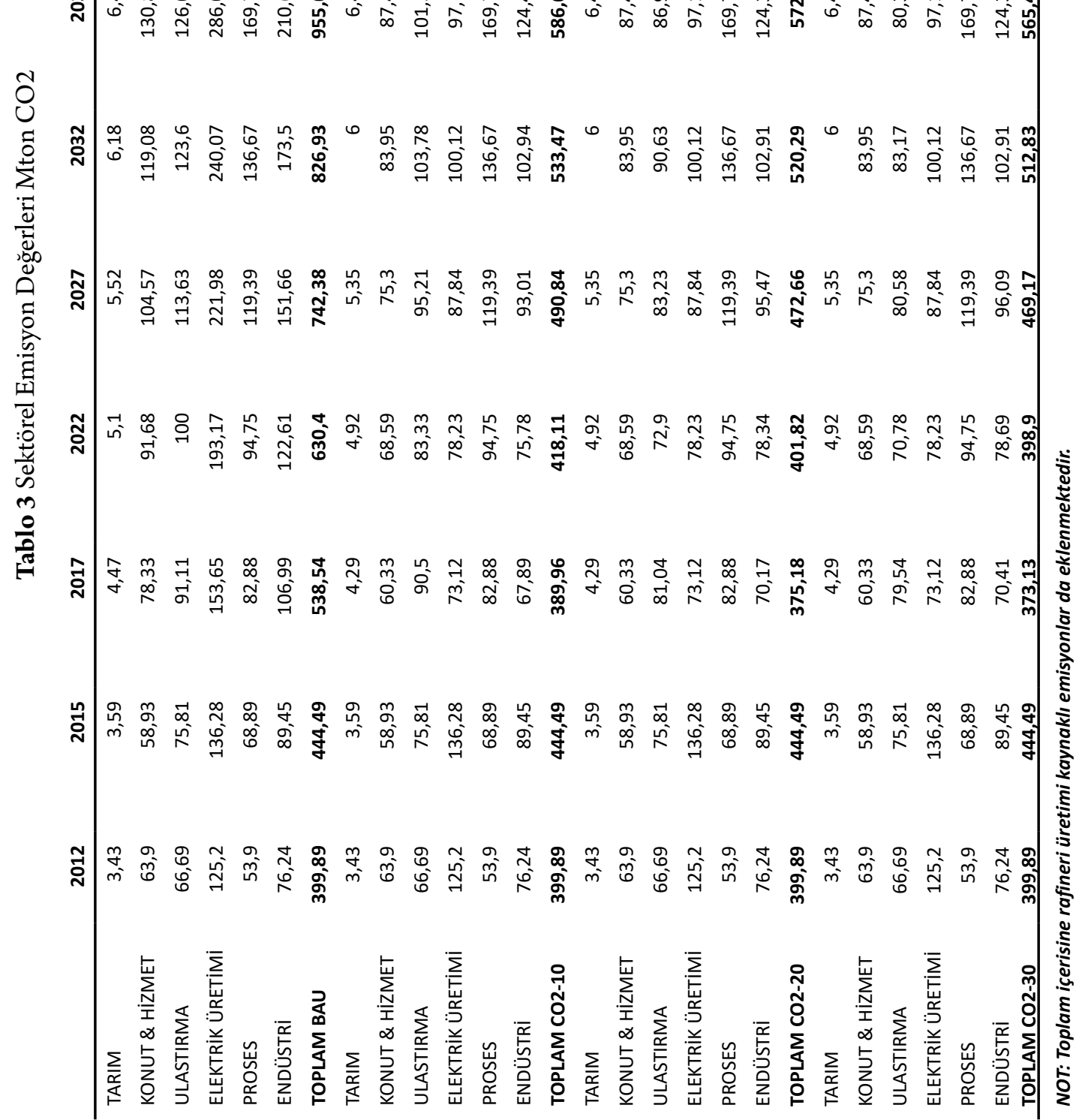




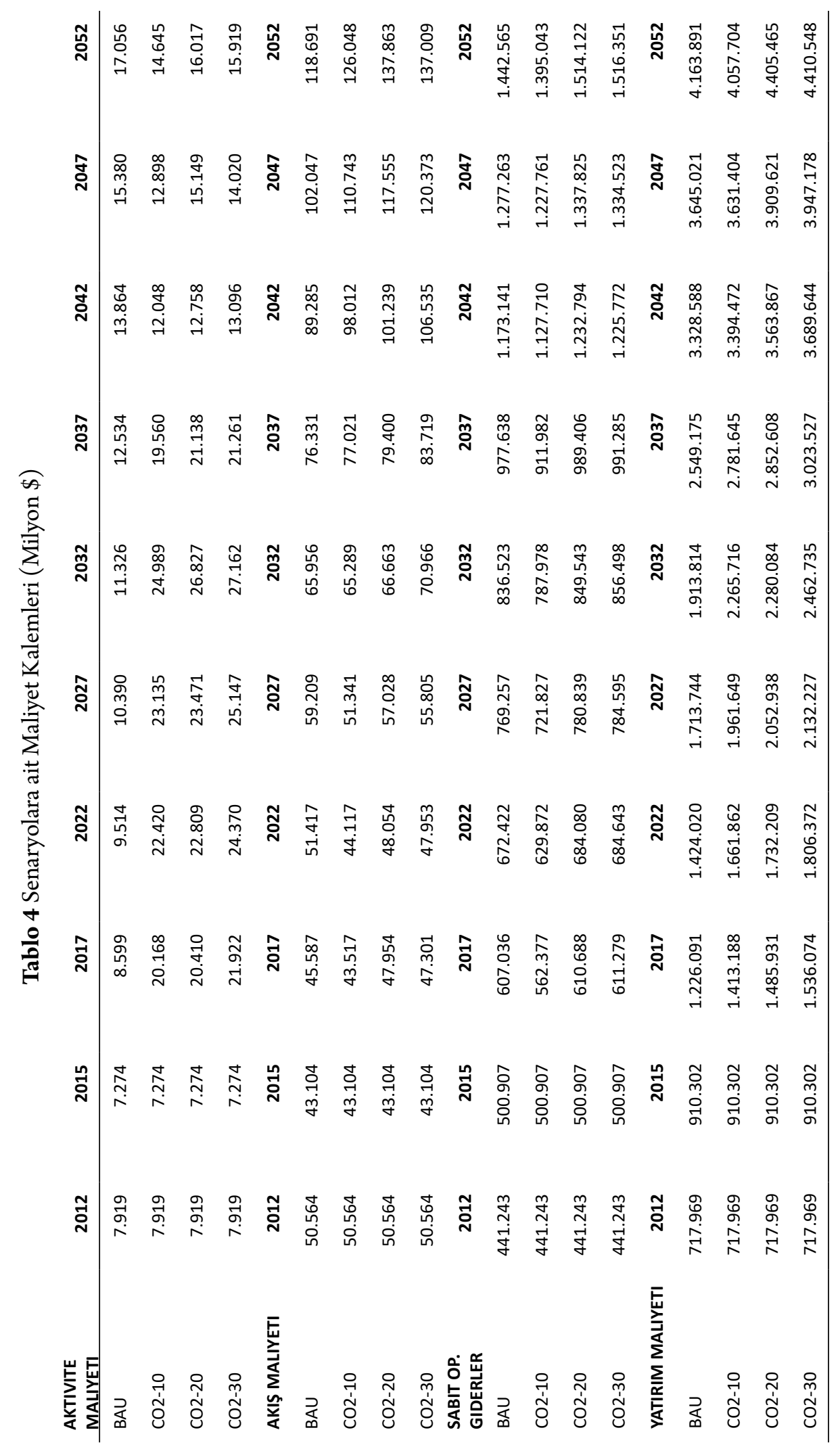




\section{Kaynakça}

Bhattacharyya, Subhes C. ve Govinda R. Timilsina. “A review of energy system models", International Journal of Energy Sector Management, Cilt 4, No.4, 2010, s.494-518.

Bretona, Michèle et.al. "A Differential Game of Joint Implementation of Environmental Projects" EJOR, Cilt 41, 2005, s.1737-1749.

Böhringer, Christoph ve Thomas F. Rutherford. “Combining bottom-up and top-down”, Energy Economics Cilt 30, No.2, 2008, s.574-596.

Buehring, William A. et.al. ENPEP: An Integrated Approach for Modelling National Energy Systems, Argonne National Laboratory, Lemont, 1991.

Capros, Pantelis et.al. "Short and medium term modeling and problems of models linkage", Energy, Cilt 15, 1990, s.301-324.

"Climate Change Indicators in the United States", EPA, 2014, https://www3.epa.gov/climatechange/science/ indicators/ghg/global-ghg-emissions.html, (Erişim Tarihi 17 Mart 2016).

Conte, Marc N. ve Matthew J. Kotchen. "Explaining The Price of Voluntary Carbon Offsets", National Bureau of Economic Research (NBER), Cilt.15294, 2009.

Cruz, Luis M.G. "Energy-Environment-Economy Interactions: An Input-Output Approach Applied to the Portuguese Case", Environment and Development: Globalisation \& the Challenges for Local \& International Governance, Sousse, Tunisia, 2002.

Çiçek, Hüseyin G. ve Serdar Çiçek. “Karbon Vergisi İle Karbon Ticareti İzinlerinin Karşılaştırılması”, İ.Ü. Siyasal Bilgiler Fakültesi Dergisi, Cilt 47, 2012, s.95-119.

Davies, Evan G.R. ve Slobodan P. Simonovic, "Global water resources modeling with an integrated model of the social-economic-environmental system”, Advances in Water Resources, Cilt 34, No.6, 2011, s. 684-700.

Dowlatabadi, Hadi. "Sensitivity of climate change mitigation estimates to assumptions about technical change", Energy Economics, Cilt 20, No.5, 1998, s.473-493.

Fisher-Vanden, Karen et.al. The second generation model of energy use, the economy, and greenhouse gas emissions, Pacific Northwest National Laboratory, 1993.

Goggins, Nygil. Hybrid Energy-Economy Model For Analysis Of Climate Policy, Yayınlanmamış Yüksek Lisans Tezi, Burnaby, Asia Royal Roads University, 2005.

Grubb, Michael et.al. "The cost of limiting fossil-fuel CO2 emissions: a survey and analysis", Annual Review of Energy and the Environment, Cilt 18, 1993, s.397-478.

Herbst, Andrea et.al. "Introduction to Energy Systems Modelling", Swiss Society of Economics and Statistics, Cilt 148, No.2, 2012, s.111-135.

Hainoun, Ali et.al. "Analysis Of The Syrian Long-Term Energy And Electricity Demand Projection Using The End-Use Methodology", Energy Policy, Cilt 34, No.14, 2006, s.1958-1970.

Hourcade, Jean C. et.al. "Estimating the costs of mitigating greenhouse gases", Economic and social dimensions of climate change, 1996, s.263-296.

Hourcade, Jean C. vd. "Hybrid Modeling, New Answers to Old Challenges", Introduction to the Special Issue of The Energy Journal, Cilt 2, 2006, s.1-12.

Howells, Mark I. et.al. "OSeMOSYS: The Open Source Energy Modeling System An introduction to its ethos, structure and development”, Energy Policy, Cilt 39, 2011, s.5850-5870.

Jaccard, Mark ve Nic Rivers. "Useful models for simulating policies to inducetechnological change", Energy Policy, Cilt 34, No.15, 2005, s.2028-2047.

Jia, Lui et.al. "Scenario Analysis Of China's Future Energy Demand Based On TIMES Model System", Energy Procedia, Cilt 5, 2011, s. 1803-1808. 
Karakaya, Etem. Küresel Isinma ve Kyoto Protokolü İklim Değişikliğinin Bilimsel, Ekonomik ve Politik Analizi, İstanbul, Bağlam Yayıncılık, 2008.

Kemfert, Claudia. "Climate Coalitions and International Trade: Assessment of Cooperation Incentives by Issue Linkage”, Energy Policy, Cilt 32, 2004, s.455-465.

Kumbaroglu, Gurkan S. "A model for long-term global air quality and development of efficient control strategies in Turkey", European Journal of Operations Research, Cilt 102, 1997, s. 380- 392.

Kumbaroglu, Gurkan S. "Environmental taxation within a bottom-up framework of energy-economy interactions: The model ENVEES, Proceedings of the Methodical Workshop on Approaches in the Integration of Energy and Economy Models for the Evaluation of Future Strategies", University of Stuttgart Institute of Energy Economics and the Rational Use of Energy, 2002, s.93-103.

Kumbaroglu, Gurkan S. ve Reinhard Madlener. "Energy and Climate Policy Analysis with the Hybrid BottomUp Computable General Equilibrium Model SCREEN: The Case of the Swiss CO2 Act”, Annals of Operations Research, Cilt 121, No.1, 2003, s. 181-203.

Loulou, Richard et.al. "Documentation for the MARKAL Family of Models”, 2004, http://www.iea-etsap.org/ web/mrkldoc-i_stdmarkal.pdf, (Erişim Tarihi 20 Haziran 2016),

Loulou, Richard et.al. "Documentation for the TIMES model, Part II. Energy technology systems analysis programme" (ETSAP), 2005, http://www.iea-etsap.org/web/docs/timesdoc-intro.pdf (Erişim Tarihi 20 Haziran 2016).

Löschel, Andreas. "Technological change in economic models of environmental policy: a survey”, Ecological Economics, Cilt 43, 2002, s.105-126.

Messner, Sabine ve Leo Schrattenholzer."MESSAGE-MACRO: linking an energy supply model with a macroeconomic module and solving it iteratively“, Energy, Cilt 25, No.3, 2000, s.267-282.

Montgomery, W. David. "Markets in Licences and Efficient Pollution Control Programs", Journal of Economic Theory, Cilt 5, 1972, s.395-418.

Mundaca, Luis et.al. "Evaluating Energy Efficiency Policies with Energy-Economy Models", Annual review of environment and resources, Cilt 35, No.1, 2010, s.305-344.

Nordhaus, William D. ve Zili Yang. "A Regional Dynamic General-Equilibrium Model of Alternative Climate Change Strategies", American Economic Review, Cilt 886, 1996, s.741-765.

Pollin, Robert et.al. The Economic Benefits of Investing in Clean Energy: How the Economic Stimulus Program and New Legislation can Boost US Economic Growth and Employment. Published Studies, 2009.

Proenca, Sara A. ve Miguel St. Aubyn. “Hybrid Top-down/Bottom-up model for energy policy analysis in a small open economy - the Portuguese case”, 2009, http://ideas.repec.org/a/eee/eneeco/v38y2013icp176-185. html, (Erişim Tarihi 20 Kasım 2016).

Rafaj, Peter ve Sokrates Kypreos. "Internalisation of external cost in the power generation sector: Analysis with Global Multi-regional MARKAL model”, Energy Policy, Cilt 35, 2007, s.828-843.

Ramachandra, T.V. "RIEP: Regional integrated energy plan“, Renewable and Sustainable Energy Reviews, Cilt 13, 2009, s.285-317.

Richey, Cooper. "Methodology for tax rebate analysis", 1998, http://endusellbl.gov/SharedData/taxmethod. rtf, (Erişim Tarihi 15 Kasım 2016).

Scott, Michael J. et.al. "The impact of DOE building technology energy efficiency programs on US employment, income, and investment", Energy Economics, Cilt 30, No.5, 2008, s.2283-2301.

Seebregts, Ad J. et.al. "Energy/Environmental Modeling with the MARKAL Family of Models", Energy and Environment, 2001, s.3-5.

Sumner, Jenny et.al. "Carbon Taxes: A Review of Experience and Policy Design Considerations", Colorado, National Renewable Energy Laboratory, 2009. 
Tol, Richard S.J. "On the Optima Control of Carbon Dioxide Emissions: An Application of Fund", Environmental Modelling and Assessment, Cilt 2, 1997, s.151-163.

TÜIK, 2013 Greenhouse Gas Emissions Inventory, 2013, http://www.turkstat.gov.tr/PreHaberBultenleri. do?id=13482, (Erişim Tarihi 20 Kasım 2016).

Vaillancourt, Kathleen et.al. "The role of nuclear energy in long-term climate scenarios: An analysis with the World-TIMES model”, Energy Policy, 2008, s.2296-2307.

Weaver, Andrew J. et.al. "Long term climate implications of 2050 emission reduction targets", Geophysical Research Letters, Cilt 34, 2007.

Yang, Z., R. S. et.al. The MIT Emissions Prediction and Policy Analysis (EPPA) Model, Report to The MIT Joint Program on the Science and Policy of Global Change, Massachusetts, 1996.

Zhang, Bin ve Liang Xu. "Multi-item Production Planning With Carbon Cap And Trade Mechanism", International Journal of Production Economics, Cilt 144, 2013, s.118-127. 